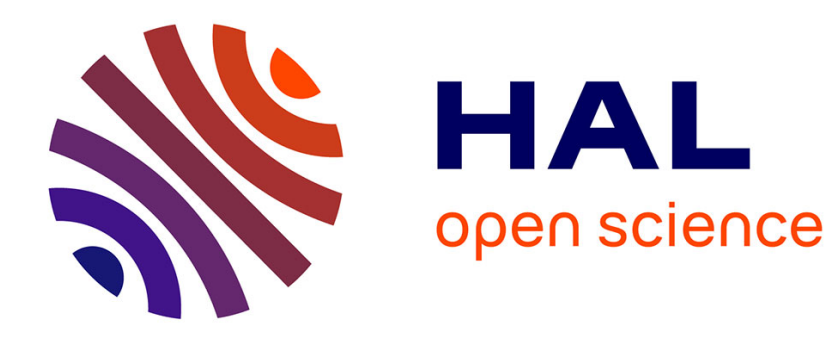

\title{
Cross-borehole slug test analysis in a fractured limestone aquifer.
}

Olivier Audouin, Jacques Bodin

\section{To cite this version:}

Olivier Audouin, Jacques Bodin. Cross-borehole slug test analysis in a fractured limestone aquifer.. Journal of Hydrology, 2008, 348, pp.510-523. 10.1016/j.jhydrol.2007.10.021 . hal-00260617

\section{HAL Id: hal-00260617 https://hal.science/hal-00260617}

Submitted on 4 Mar 2008

HAL is a multi-disciplinary open access archive for the deposit and dissemination of scientific research documents, whether they are published or not. The documents may come from teaching and research institutions in France or abroad, or from public or private research centers.
L'archive ouverte pluridisciplinaire $\mathbf{H A L}$, est destinée au dépôt et à la diffusion de documents scientifiques de niveau recherche, publiés ou non, émanant des établissements d'enseignement et de recherche français ou étrangers, des laboratoires publics ou privés. 


\title{
Cross-borehole slug test analysis in a fractured limestone
}

\section{aquifer.}

\author{
by Olivier Audouin ${ }^{1,2,3}$ and Jacques Bodin ${ }^{1,2}$ \\ ${ }^{1}$ Université de Poitiers, FRE 3114 HydrASA, 40 av. Recteur Pineau, 86022 Poitiers Cedex, France \\ ${ }^{2}$ CNRS/INSU, FRE 3114 HydrASA, 40 av. Recteur Pineau, 86022 Poitiers Cedex, France \\ ${ }^{3}$ Now at SEMM LOGGING, Les Maufras, 18360 Vesdun, France
}

\begin{abstract}
This work proposes new semi-analytical solutions for the interpretation of cross-borehole slug tests in fractured media. Our model is an extension of a previous work by Barker (1988) and Butler and Zhan (2004). It includes inertial effects at both test and observation wells and a fractional flow dimension in the aquifer. The model has 5 fitting parameters: flow dimension $n$, hydraulic conductivity $K$, specific storage coefficient Ss, and effective lengths of test well $L e$ and of observation well $L e_{o}$. The results of a sensitivity analysis show that the most sensitive parameter is the flow dimension $n$. The model sensitivity to other parameters may be ranked as follows: $K>L e \sim L e_{o}>S s$. The sensitivity to aquifer storage remains one or two orders of magnitude lower than that to other parameters. The model has been coupled to an automatic inversion algorithm for facilitating the interpretation of real field data. This inversion algorithm is based on a Gauss-Newton optimization procedure conditioned by re-scaled sensitivities. It has been used to interpret successfully cross-borehole slug test data from the Hydrogeological Experimental Site (HES) of Poitiers, France, consisting of fractured and karstic limestones. HES data provide flow dimension values ranging between 1.6 and 2.5, and hydraulic conductivity values ranging between $4.4 \times 10^{-5}$ and $7.7 \times 10^{-4}$ m.s ${ }^{-1}$. These values are consistent with previous interpretations of single-well slug tests. The results of the sensitivity analysis are confirmed by calculations of relative errors on parameter estimates, which show that accuracy on $n$ and $K$ is below $20 \%$ and that on Ss is about one order of magnitude. The K-values
\end{abstract}


interpreted from cross-borehole slug tests are one order of magnitude higher than those previously interpreted from interference pumping tests. These findings suggest that cross-borehole slug tests focus on preferential flowpath networks made by fractures and karstic channels, i.e. the head perturbation induced by a slug test propagates only through those flowpaths with the lowest hydraulic resistance. As a result, cross-borehole slug tests are expected to identify the hydrodynamic properties of karstic channels and fracture flowpaths, and may be considered as complementary to pumping tests which more likely provide bulk properties of the whole fracture/karstic-channel/matrix system.

\section{Keywords}

Slug test; Cross-borehole; Fractured aquifer; Inertial effects; Fractional flow

\section{Introduction}

Slug testing is a widely used field method for assessing the hydraulic properties of an aquifer. Since the early work of Hvorslev (1951), a number of theoretical models have been developed for the interpretation of slug test experiments, see e.g. the extensive review by Butler Jr. (1997) and more recent works by McElwee and Zenner (1998), Zlotnik and McGuire (1998a), Zurbuchen et al. (2002), Butler Jr. and Zhan (2004), Chen (2006) and Yeh and Yang (2006). Most of these models assume homogeneous, isotropic, and continuous aquifer properties. Their use in fractured rock environments may thus be questioned because of the channelized nature of flowpaths in such media (see e.g. Tsang and Neretnieks (1998), Audouin et al., Flowpath structure in a limestone aquifer: multi-borehole logging investigations at the Hydrogeological Experimental Site of Poitiers, France. submitted at Hydrogeology Journal, (2007)). A set of analytical slug test models accounting for discrete flowpaths has been developed by Karasaki et al. (1988) but, as pointed out by Butler Jr. (1997) and Lee and Lee (1999), these models are of little practical use because they involve a large number of input parameters (one set of hydraulic parameters per individual flowpath), which can be hardly assessed independently from each other in real field studies. This leads to a multiplication of fitting parameters and raises the classical problem of non-uniqueness. 
Karasaki et al. (1988) acknowledge that many combinations of model parameters may lead to similar responses in their models. Although fractured aquifers are inherently heterogeneous, the use of homogenized models involving a reduced number of parameters may thus be considered as a practical alternative. A suited modelling approach is that proposed by Barker (1988), who developed a theoretical framework involving fractional flow dimensions to conceptualize the channelized geometry of flow in fractured media. The generalized radial flow (GRF) model of Barker (1988) has been widely used for interpreting interference pumping tests (e.g. Leveinen 2000, Walker and Roberts 2003, Kuusela-Lahtinen et al. 2003, Le Borgne et al. 2004) but surprisingly has not been so popular for slug test interpretation (Novakowski and Bickerton 1997). Its applicability is limited in high-permeability fractured aquifers because it does not account for inertial effects, which may lead to underdamped (i.e. oscillatory) slug test responses (Van Der Kamp 1976, Kipp Jr. 1985, McElwee and Zenner 1998, Zlotnik and McGuire 1998a, Zlotnik and McGuire 1998b, Butler Jr. and Zhan 2004, Audouin and Bodin 2007). Furthermore, the slug test model proposed by Barker (1988) does not allow to interpret response data from observation wells located at a distance from the test well (e.g. Novakowski 1989), which, when available, can considerably improve the reliability of parameter estimates (McElwee et al. 1995a, 1995b, Butler Jr. 1997). A new semi-analytical model is developed in the present paper, on the basis of the previous works of Barker (1988) and Butler Jr. and Zhan (2004). This model enables to interpret cross-borehole slug tests while accounting for (i) fractional flow dimension in the aquifer, and (ii) inertial effects at both the test and observation wells. The governing equations and the derivation of the semi-analytical solution are presented in the first part of this paper. In section 2, the influence of inertial effects and fractional flow dimension are illustrated qualitatively by comparing the synthetic slug-test responses simulated with our model to those obtained by Cooper Jr. et al. (1967) and Butler Jr. and Zhan (2004). Section 3 discusses the results of a sensitivity analysis in the perspective of field data interpretation. In the last section, we present interpretation results from a series of cross-borehole slug test experiments performed in a fractured limestone aquifer (Hydrogeological Experimental Site of Poitiers, France).

\section{Model theory}


The model developed here is based on the previous works of Barker (1988) and Butler Jr. and Zhan (2004). The aquifer is assumed to be confined, of infinite areal extent and constant thickness. While the model of Butler Jr. and Zhan (2004) enables to account for partially and fully penetrating wells, we restrict ourselves to the case of fully penetrating wells for simplifying convenience. Both the test well and observation well are considered screened (or open) throughout the thickness of the aquifer. Well skin effects are assumed to be negligible. The propagation/dissipation of the pressure-head disturbance induced by the slug test is assumed to occur radially in the aquifer, into a $n$-dimensional homogeneous and isotropic flow structure. For the test well and adjacent aquifer, the governing equations and associated initial/boundary conditions are:

- Aquifer flow (Barker 1988):

$$
\begin{gathered}
S_{s} \frac{\partial h(r, t)}{\partial t}=\frac{K}{r^{n-1}} \frac{\partial}{\partial r}\left(r^{n-1} \frac{\partial h(r, t)}{\partial r}\right) \\
h(r, t=0)=0 \\
h\left(r=r_{w}, t\right)=h_{s}(t) \\
h(r=\infty, t)=0
\end{gathered}
$$

- Mass balance in the test well (Barker 1988):

$$
\begin{aligned}
& \pi r_{c}^{2} \frac{d H(t)}{d t}=\left.K b^{3-n} \alpha_{n} r_{w}^{n-1} \frac{\partial h(r, t)}{\partial r}\right|_{r=r_{w}} \\
& \alpha_{n}=\frac{2 \pi^{\mathrm{n} / 2}}{\Gamma(n / 2)}, \Gamma(\mathrm{x}) \text { the gamma function }
\end{aligned}
$$

- Momentum balance in the test well (Butler Jr. and Zhan 2004):

$$
\frac{d^{2} H(t)}{d t^{2}}+\frac{8 v L}{r_{c}^{2} L e} \frac{d H(t)}{d t}+\frac{g}{L e} H(t)=\frac{g}{L e} h_{s}(t)
$$


with

$$
L=l+\left(\frac{r_{c}^{4}}{r_{w}^{4}}\right)\left(\frac{b}{2}\right) \text { (Butler 2002) }
$$

The initial conditions in the test well are:

$$
\begin{aligned}
& H(t=0)=H_{0} \\
& \frac{d H(t=0)}{d t}=V_{0}
\end{aligned}
$$

where

$b \quad$ aquifer thickness [L]

$g$ gravitational acceleration $\left[\mathrm{L} / \mathrm{T}^{2}\right]$

$H(t) \quad$ deviation of hydraulic head in the test well from static conditions [L]

$H_{0} \quad$ initial slug-head increase in the test well [L]

$V_{0} \quad$ initial velocity of water level in the test well as a result of slug test initiation [L/T]

$h(r, t) \quad$ deviation of hydraulic head in aquifer from static conditions [L]

$h_{s}(t)$ deviation of hydraulic head within the screen of the test well from static conditions [L]

Le effective length of water column in well (Kipp Jr. 1985) [L]

l length of water column above the top of screen [L]

$r \quad$ radial distance from the centre of the test well [L]

$r_{c} \quad$ casing radius in the test well [L]

$r_{w}$ screen radius in the test well or borehole radius in the case of open well [L]

$\mathrm{S}_{\mathrm{s}} \quad$ specific storage coefficient of aquifer $\left[\mathrm{L}^{-1}\right]$

$\mathrm{K}$ hydraulic conductivity of aquifer [L/T]

$v \quad$ kinematic viscosity of water $\left[\mathrm{L}^{2} / \mathrm{T}\right]$

$n \quad$ flow dimension (Barker 1988)

The Laplace transform solution of (1) with its associated initial/boundary conditions (2)-(4) is in the form (Barker 1988, eq. 15):

$$
\bar{h}(r, p)=A(p) r^{\mu} K_{\mu}(\lambda r)
$$




$$
\begin{gathered}
\mu=1-n / 2 \\
\lambda^{2}=p S_{s} / K
\end{gathered}
$$

where $p$ is the transform variable, $A(p)$ is a function to be determined from the boundary conditions, and $\mathrm{K}_{\mu}(\mathrm{z})$ is the K-Bessel function.

The derivative of (11) at the screen radius is:

$$
\left.\frac{\partial \bar{h}(r, p)}{\partial r}\right|_{r=r_{w}}=-A(p) \lambda r_{w}^{\mu} K_{\mu-1}\left(\lambda r_{w}\right)
$$

Taking the Laplace transform of (5) and using (14) gives:

$$
A(p)=\frac{\pi r_{c}^{2}\left(H_{0}-p \bar{H}(p)\right)}{K b^{3-n} \alpha_{n} r_{w}^{n / 2} \lambda K_{\mu-1}\left(\lambda r_{w}\right)}
$$

Equation (11) becomes:

$$
\bar{h}(r, p)=\frac{\pi r_{c}^{2}\left(H_{0}-p \bar{H}(p)\right) r^{\mu} K_{\mu}(\lambda r)}{K b^{3-n} \alpha_{n} r_{w}^{n / 2} \lambda K_{\mu-1}\left(\lambda r_{w}\right)}
$$

Taking the Laplace transform of (7) with its associated initial conditions (9-10) and using (16) gives the following semi-analytical solution for the transient water level in the test well:

$$
\bar{H}(p)=\frac{(\gamma+\beta+p) H_{0}+V_{0}}{(\gamma+\beta+p) p+\frac{g}{L e}}
$$

where

$$
\begin{gathered}
\gamma=\frac{g \pi r_{c}^{2} r_{w}{ }^{1-n} K_{\mu}\left(\lambda r_{w}\right)}{L e K b^{3-n} \alpha_{n} \lambda K_{\mu-1}\left(\lambda r_{w}\right)} \\
\beta=\frac{8 v L}{r_{c}^{2} L e}
\end{gathered}
$$


The semi-analytical solution for the hydraulic head in the aquifer is obtained by substitution of (17) in (16)

$$
\bar{h}(r, p)=\frac{\pi r_{c}^{2} r^{\mu} K_{\mu}(\lambda r)}{K b^{3-n} \alpha_{n} r_{w}^{n / 2} \lambda K_{\mu-1}\left(\lambda r_{w}\right)}\left(\frac{H_{0} \frac{g}{L e}-p V_{0}}{(\gamma+\beta+p) p+\frac{g}{L e}}\right)
$$

The derivation of the semi-analytical solution of the water level in the observation well is made in the same way as above. Basing on the work of Barker (1988), Zhan and Butler Jr. (2003), and Butler Jr. and Zhan (2004), the governing equations and associated initial/boundary conditions can be written as:

- Aquifer flow:

$$
\begin{gathered}
S_{s} \frac{\partial w\left(r_{o}, t\right)}{\partial t}=\frac{K}{r_{o}^{n-1}} \frac{\partial}{\partial r_{o}}\left(r_{o}^{n-1} \frac{\partial w\left(r_{o}, t\right)}{\partial r_{o}}\right) \\
w\left(r_{o}, t=0\right)=0 \\
w\left(r_{o}=r_{w o}, t\right)=w_{s o}(t) \\
w\left(r_{o}=\infty, t\right)=0
\end{gathered}
$$

- Mass balance in the observation well:

$$
\pi r_{c o}^{2} \frac{d W(t)}{d t}=\left.K b^{3-n} \alpha_{n} r_{w o}^{n-1} \frac{\partial w\left(r_{o}, t\right)}{\partial r_{o}}\right|_{r_{o}=r_{\text {wo }}}
$$

- Momentum balance in the observation well:

$$
\frac{d^{2} W(t)}{d t^{2}}+\frac{8 v L_{o}}{r_{c o}^{2} L e_{o}} \frac{d W(t)}{d t}+\frac{g}{L e_{o}} W(t)=\frac{g}{L e_{o}}\left(w_{s o}(t)+h\left(r_{L}, t\right)\right)
$$

with

$$
L=l_{o}+\left(\frac{r_{c o}^{4}}{r_{w o}^{4}}\right)\left(\frac{b}{2}\right)
$$


The initial conditions in the test well are:

$$
\begin{gathered}
W(t=0)=0 \\
\frac{d W(t=0)}{d t}=0
\end{gathered}
$$

where

$$
\begin{gathered}
W(t) \text { deviation of water level in the observation well from static conditions [L] } \\
w\left(r_{o}, t\right) \text { deviation of hydraulic head in aquifer from static conditions [L] } \\
w_{s o}(t) \text { deviation of hydraulic head within the screen of the observation well from static conditions }
\end{gathered}
$$

$L e_{o} \quad$ effective length of water column in the observation well [L]

$l_{o} \quad$ length of water column above the top of screen [L]

$r_{o} \quad$ radial distance from the centre of the observation well [L]

$r_{c o} \quad$ casing radius in the observation well [L]

$r_{\text {wo }} \quad$ screen radius in the observation well or borehole radius in the case of open well [L]

$r_{L} \quad$ distance from the test well to the observation well [L]

The Laplace transform solution of the hydraulic head in the aquifer in relation to the water level in the observation well is derived analogously to (16):

$$
\bar{w}(r, p)=\frac{-\pi r_{c o}^{2} p \bar{W}(p) r_{o}^{\mu} K_{\mu}\left(\lambda r_{o}\right)}{K b^{3-n} \alpha_{n} r_{w o}^{n / 2} \lambda K_{\mu-1}\left(\lambda r_{w o}\right)}
$$

Substitution of (30) in the Laplace transform of (26) gives the following semi-analytical solution for the transient water level in the observation well:

$$
\bar{W}(p)=\frac{\frac{g \pi r_{c}^{2} r_{L}{ }^{\mu} K_{\mu}\left(\lambda r_{L}\right)}{L e_{o} K b^{3-n} \alpha_{n} r_{w}^{n / 2} \lambda K_{\mu-1}\left(\lambda r_{w}\right)}\left(\frac{H_{0} \frac{g}{L e}-p V_{0}}{(\gamma+\beta+p) p+\frac{g}{L e}}\right)}{\left(\gamma_{o}+\beta_{o}+p\right) p+\frac{g}{L e_{o}}}
$$

where 


$$
\begin{gathered}
\gamma_{o}=\frac{g \pi r_{c o}^{2} r_{w o}{ }^{1-n} K_{\mu}\left(\lambda r_{w o}\right)}{L e_{o} K b^{3-n} \alpha_{n} \lambda K_{\mu-1}\left(\lambda r_{w o}\right)} \\
\beta_{o}=\frac{8 v L_{o}}{r_{c o}^{2} L e_{o}}
\end{gathered}
$$

For a flow dimension $n=2$, (17) and (31) reduce, respectively, to Equations 11 and 24 of Butler Jr. and Zhan (2004) for the case of fully penetrating wells. The computation of slug test responses in the realtime domain requires numerical inversion of Laplace transform solutions. In this work, we have used the MATLAB® routine "Invlap.m” written by Hollenbeck (1998), which is based on the De Hoog et al. (1982) algorithm.

\section{Slug test response at the observation well: influence of inertial effects and fractional flow dimension}

The influence of inertial effects at both the test well and observation well is evaluated below by comparing cross-borehole slug test responses corresponding to the model of Cooper Jr. et al. (1967) to responses calculated from (31) using a flow dimension $n=2$. Computing $h\left(r_{L}, t\right)$ from (20) allows to account only for inertial effects in the test well. The first comparison illustrated in Fig. 1 corresponds to the following set of parameters: $K=3 \times 10^{-5} \mathrm{~m} / \mathrm{s}, S s=5 \times 10^{-7} \mathrm{~m}^{-1}, b=100 \mathrm{~m}, r_{L}=30 \mathrm{~m}, L e=L e_{o}=50 \mathrm{~m}, r_{w}=$ $r_{c}=r_{\text {wo }}=r_{\mathrm{co}}=0.11 \mathrm{~m}, H_{0}=1 \mathrm{~m}$. Resulting head-time curves show the marked influence of inertial effects in the observation well as compared to those in the test well. Slug test responses calculated with the model of Cooper Jr. et al. (1967) and from (20) are quite similar. Inertial effects in the test well cause an apparent delay on the propagation of the slug-induced perturbation, but the time of maximum amplitude remains unchanged. Both curves are identical for long times. Taking into account inertial effects at the observation well leads to significant changes in the response, with a decrease of the perturbation peak amplitude and a shift of the maximum amplitude time from 14.5 to $27.5 \mathrm{~s}$. This time shift is due to the negative deviation of hydraulic head within the observation well screen $w_{s o}(t)$ for the first 30s (see Fig. 1), which thwarts the head $h\left(r_{L}, t\right)$ in the resulting signal $W(t)$, see Eq. 26. Increasing $K$ by one order of 
magnitude $\left(K=3 \times 10^{-4} \mathrm{~m} / \mathrm{s}\right.$ ) leads to the oscillatory response curves illustrated in Fig. 2. As observed above, inertial effects in the observation well involve a time shift of the response signal, but in that case the dephasing between $h\left(r_{L}, t\right)$ and $w_{s o}(t)$ produces an amplification of the slug test response. Fig. 1 and 2 clearly show the significant influence of inertial effects at the observation well, which, if neglected, may lead to a misinterpretation of cross-borehole slug test data.

The influence of flow dimension is illustrated in Fig. 3. The parameters are the same as used previously except for the hydraulic conductivity $K$ whose value was set at $1.5 \times 10^{-4} \mathrm{~m} / \mathrm{s}$. Three flow dimension values were considered: $n=1.8, n=2.0$, and $n=2.2$. For $n=2.0$, the slug test response calculated from (31) is strictly identical to that given by the model of Butler Jr. and Zhan (2004) and appears critically damped. As visible in Fig. 3, variations in flow dimension values have a large impact on the calculated curves. For $n=1.8$, the slug test response is underdamped, with the same oscillation period as for $n=2.0$. A higher amplitude of the first peak and a smaller attenuation maintain the oscillatory character of head response at long times. For $n=2.2$, the slug test response is overdamped, with a maximum amplitude time similar to that of oscillatory responses. The decrease of peak amplitude as compared to 2D flow is consistent with the increase of flow area. Note that the head responses calculated with fractional dimensions may be roughly approximated with a 2D flow assumption using modified hydrodynamic parameters (e.g. $n=2.0$, $K=1.1 \times 10^{-4} \mathrm{~m} / \mathrm{s}$ and $S_{s}=1 \times 10^{-6} \mathrm{~m}^{-1}$ instead of $n=2.2, K=1.5 \times 10^{-4} \mathrm{~m} / \mathrm{s}$ and $S_{s}=5 \times 10^{-7} \mathrm{~m}^{-1}$ ), but the corresponding curves are not strictly identical at intermediate and long times (Fig. 3).

\section{Sensitivity Analysis}

The purpose of a sensitivity analysis is to investigate the behavior of slug test responses calculated from (31) in relation to variations of input parameters. The aim is to identify the parameters that have the largest influence on the shape of the slug test responses, which enables to assess the reliability of parameter estimates when interpreting real field slug test data. The proposed model involves five fitting parameters: $n, K, S_{s}, L e$ and $L e_{o}$. While $L e$ and $L e_{o}$ could theoretically be calculated from geometrical considerations about the well casing/screen system, several authors have noted that effective length values must often be considerably enlarged when attempting to fit real field slug test responses (Kipp Jr. 
1985, Butler Jr. 1997, McElwee and Zenner 1998). According to McElwee and Zenner (1998), this discrepancy results from several factors such as velocity distribution in the screened casing and water flow acceleration in the aquifer. Effective lengths should thus better be viewed as empirical fitting parameters when analyzing field data. Sensibility analyses in the modelling literature (see e.g. McElwee et al. 1995a and references therein) are based on either a standard sensitivity coefficient:

$$
U_{n}=\frac{\partial W(t)}{\partial n}, U_{K}=\frac{\partial W(t)}{\partial K}, U_{s_{s}}=\frac{\partial W(t)}{\partial S_{s}}, U_{L e}=\frac{\partial W(t)}{\partial L e}, U_{L e_{o}}=\frac{\partial W(t)}{\partial L e_{o}}
$$

or a normalized sensitivity coefficient:

$$
U_{n}{ }^{\prime}=n \frac{\partial W(t)}{\partial n}, U_{K}{ }^{\prime}=K \frac{\partial W(t)}{\partial K}, U_{s_{s}}{ }^{\prime}=S_{s} \frac{\partial W(t)}{\partial S_{s}}, U_{L e}{ }^{\prime}=L e \frac{\partial W(t)}{\partial L e}, U_{L e_{o}}{ }^{\prime}=L e_{o} \frac{\partial W(t)}{\partial L e_{o}}
$$

As emphasized by McElwee et al. (1995a, 1995b) and Kabala (2001), the normalized sensitivity analysis is the approach best suited for evaluating the relative significance of different dimension parameters. The analysis below is therefore based on this approach, but standard sensitivity coefficients have also been computed for inversion purposes (see section 5). Owing to the semi-analytical character of (33) and (34), a perturbation approximation approach has been used for computing the sensitivity derivatives:

$$
\frac{\partial W(t)}{\partial A} \approx \frac{W_{A+\delta A}(t)-W_{A}(t)}{\delta A}
$$

where $A$ is a parameter and $\delta A$ is a small perturbation added to this parameter $(0.1 \% A)$. Fig. 4 and 5 display slug-test response and standard/normalized sensitivity curves for overdamped and underdamped cases, respectively. These analyses were based on the same well configuration as previously described and the following sets of parameters: $n=2, K=5 \times 10^{-5} \mathrm{~m} / \mathrm{s}, S s=5 \times 10^{-8} \mathrm{~m}^{-1}$ (overdamped response, Fig. 4 ), and $n=2, K=1.5 \times 10^{-4} \mathrm{~m} / \mathrm{s}, S s=5 \times 10^{-7} \mathrm{~m}^{-1}$ (underdamped response, Fig. 5).

The absolute amplitude of sensitity curves in Fig. 4 shows that the overdamped response is primarily sensitive to flow dimension $n$ and to a lesser extent to hydraulic conductivity $K$. The sensitivities to other parameters Le, Leo and $S_{s}$ are lower by one order of magnitude approximately. Note that the sensitivity to $n$ is much more marked in the observation well than what was found by Barker (1988) in the tested well. While Barker (1988) stated that "it should be expected that the analysis of slug test data would often fail to produce a unique dimension", our results indicate that cross-borehole slug testing may provide a 
reliable assessment of the flow dimension. The normalized sensitivity to $n$ is negative at short times and reaches its maximum amplitude at the same time as the $W(\mathrm{t})$ peak. Then, the sensitivity slope reverses and the curve rises to a second peak of lower amplitude and higher asymmetry. A comparison between the $n$ sensitivity curve and the head response $W(t)$ indicates a negative correlation between the two curves at short times and a positive correlation at intermediate and long times. This means that higher flow dimensions may lead to lower peak amplitude and higher tailing in the head response at observation well, which is consistent with the results displayed in Fig. 3. The normalized sensitivity to $K$ shows a first positive peak located slightly before the $W(t)$ peak, which indicates that higher $K$-values may lead to slug test responses of higher amplitude and shifted towards short times. The second peak in the $K$-sensitivity curve is negative and has a more pronounced tailing than the first one. This negative sensibility means that higher hydraulic conductivities may reduce the asymmetry of slug test responses. Sensitivity curves for $L e$ and $L e_{0}$ are identical and show first a negative part followed by a positive peak located after the $W(\mathrm{t})$ peak time, which indicates that an increase in effective lengths involves a moving of the $W(\mathrm{t})$ peak towards long times. The sensitivity to $S_{s}$ is fifty times lower than that to $n$, which corroborates the wellknown limitation of the slug test method for the characterization of aquifer storage properties. Note that the $S_{s}$-sensitivity curve is nevertheless physically consistent since its overall negativity indicates that higher storage may reduce the amplitude of the slug test response.

Sensitivity analysis for the underdamped case is illustrated in Fig. 5. As for the overdamped case, the head response in the observation well is most sensitive to $n$. The $n$-sensitivity curve displays an oscillatory behaviour dephased with that of the head signal in the observation well. It must be observed that the amplitude of the second peak is higher than that of the first and third peaks, which, combined with phase displacement, indicates that higher flow dimensions may attenuate the oscillatory behaviour of the slug test response. Overdamped responses may thus be favoured by flow dimensions higher than two, as previously suggested by Fig. 3. The sensitivity curves for $L e$ and $L e_{o}$ are again identical but their overall amplitude is 50 times higher in Fig. 5 than in Fig. 4. The sensibility of underdamped responses to $L e$ and $L e_{o}$ is thus on the same order than that to hydraulic conductivity $K$ but differences in sensibility curves at short times ensure a proper distinction of the causality of parameters, which favours independent estimates of these parameters. The $L e / L e_{o}$ sensitivity curve and $W(t)$ signal are quite similar 
in shape but are dephased. As a consequence, modifications in effective length values affect strongly the duration of oscillation periods in the slug test response. The sensitivity to hydraulic conductivity is very low at short times and the $K$-value has thus no influence on the amplitude of the first peak in the head response. The amplitude of the $K$-sensitivity curve increases at intermediate times and is then in phase with the $W(t)$ signal, which indicates that higher $K$-values may reduce the damping factor in the slug test response. As for the overdamped case, the sensitivity to aquifer storage remains one or two orders of magnitude lower than that to other parameters. Caution should thus be exercised with $S_{s}$-estimates. The first peak in the $S_{s}$-sensitivity curve is negative and is located slightly before the $W(t)$ peak, which means that higher storage values may delay the first $W(t)$ peak in the slug test response.

\section{Automatic inversion of slug test data}

In order to facilitate the interpretation of real-field data, the proposed model may be coupled to an automatic calibration procedure. The method adopted here is that developed by Delay et al. (2006) for the inversion of hydraulic interference pumping tests. It relies on a Gauss-Newton optimization algorithm conditioned by re-scaled sensitivities to the model parameters. For the set of parameter $A$, the standard optimization scheme may be written as (Nocedal and Wright 1999):

$$
A^{k+1}=A^{k}-\left(J_{\xi^{k}}^{T} \cdot J_{\xi^{k}}\right)^{-1} \cdot\left(J_{\xi^{k}}^{T} \cdot \xi^{k}\right)
$$

where $k$ is the iteration index, $\xi$ is the 1D matrix error between simulated and observed hydraulic heads, and $J_{\xi}$ is the Jacobian error matrix of dimension $m \times p$ :

$$
J_{\xi}=\left[\frac{\partial \xi_{i}}{\partial A_{j}}, i=1 . . m, j=1 . . p\right]=\left[\begin{array}{cccc}
\frac{\partial \xi_{1}}{\partial A_{1}} & \cdots & \cdots & \frac{\partial \xi_{1}}{\partial A_{p}} \\
\vdots & \ddots & & \vdots \\
\vdots & & \ddots & \vdots \\
\frac{\partial \xi_{m}}{\partial A_{1}} & \cdots & \cdots & \frac{\partial \xi_{m}}{\partial A_{p}}
\end{array}\right]
$$


where $m$ and $p$ are the number of time steps in the simulated slug test response and the number of parameters, respectively. Since $\partial \xi_{i} / \partial A_{j}=\partial W_{i} / \partial A_{j}$, the Jacobian matrix stores the "standard" sensitivities of the model to parameters (see section 4). As shown in Fig. 4 and Fig. 5 (right vertical axis), these sensitivities span several orders of magnitude, which causes the matrix $J_{\xi}^{T} \cdot J_{\xi}$ to be poorly conditioned and yields a numerically ill-posed problem. In order to overcome this problem, Delay et al. (2006) propose to re-scale sensitivities to parameters by multiplying them by a scalar $c_{j}$. The new sensitivities become of about the same order of magnitude whatever $A_{j}$ and the modified sensitivity matrix is called $J_{\xi}{ }^{*}$. The modified optimization scheme is given by:

$$
\frac{A_{j}^{k+1}}{c_{j}}=\frac{A_{j}^{k}}{c_{j}}+\zeta D_{j}^{* k} \quad(j=1, \ldots, p)
$$

where $D^{* k}=-\left(J_{\xi^{k}}^{* T} \cdot J_{\xi^{k}}^{*}\right)^{-1} \cdot\left(J_{\xi^{k}}^{* T} \cdot \xi^{k}\right)$ and $\zeta$ is a scalar value enabling to control the rate of change of $A_{j}$ in the iterative algorithm.

Iterations are done until the following convergence criterion is reached:

$$
\sum_{i=1}^{m}\left(\xi_{i}^{k+1}\right)^{2}-\sum_{i=1}^{m}\left(\xi_{i}^{k}\right)^{2}<\varepsilon_{0}
$$

where $\varepsilon_{0}$ is the convergence threshold defined by the user. In this work, we have used $\varepsilon_{0}=10^{-6}$. Using the above method actually enables fast and accurate curve fitting to be performed in the case of overdamped responses, but oscillations in underdamped responses may lead to convergence difficulties. As discussed above, the duration of oscillation periods in the slug test response is mostly sensitive to effective lengths Le and Leo. In order to facilitate the convergence of the optimization algorithm, it is necessary to proceed in two steps. First, the value of $L e$ (or Leo) is fixed and the inversion is performed for the 4 other parameters $n, K, S_{s}$ and Leo (or $L e$ ). Then parameter $L e$ (or $L e o$ ) is relaxed and a second inversion is performed for the whole set of parameters, using the previous output as initial parameters. Another recommendation from practical experience is to start the calibration procedure with a specific storage value lower than that expected.

A further interest of this automatic inversion method is to allow quantification of the error $\varepsilon_{j}$ made on each parameter estimate with the following expression (Kaczmaryk and Delay 2007): 


$$
\varepsilon_{j}=\sqrt{\operatorname{Diag}_{j}\left(\left(J_{\xi^{k^{*}}}{ }^{T} . J_{\xi^{k^{*}}}\right)^{-1}\right) \sum_{i=1}^{m}\left[\frac{1}{2}\left(\xi_{i}^{k^{*}}\right)^{2}\right]}
$$

where $k^{*}$ is the last iteration in the optimization algorithm and $\operatorname{Diag}_{j}\left(\left(J_{\xi^{k^{*}}}{ }^{T} . J_{\xi^{k^{*}}}\right)^{-1}\right)$ is the diagonal term of row $j$ in the matrix $\left(J_{\xi^{k^{*}}}^{T} . J_{\xi^{k^{*}}}\right)^{-1}$.

\section{Example of model application: interpretation of cross-borehole slug test data from the Hydrogeological Experimental Site of Poitiers, France}

The Hydrogeological Experimental Site (HES) is located in a geological area called "Poitou Threshold", which makes the transition between two large Mesozoic-Cenozoic sedimentary basins, i.e. the Paris basin to the Northeast and the Aquitaine basin to the Southwest. The Poitou Threshold consists of Jurassic carbonate rocks lying on a Hercynian crystalline basement. Two limestone aquifers occur in the Jurassic carbonate series: (i) the lower and middle-Lias aquifer (5-10m thick), and (ii) the Dogger aquifer (100m thick). These two aquifers are separated by the Toarcian aquitard (20m thick), consisting of lowpermeability marls. Investigations made in the HES mainly focus on the Dogger aquifer. The experimental site includes 25 fully penetrating wells that were drilled between 2002 and 2004 down to the top of Toarcian marls located at about $125 \mathrm{~m}$ depth. These wells were arranged according to a geometric pattern of symmetry 4 ("five-spot" borehole configuration), which occupies a square area of $210 \mathrm{~m} \mathrm{x}$ $210 \mathrm{~m}$. Under natural conditions, the piezometric levels in the Dogger aquifer range from $15 \mathrm{~m}$ to $25 \mathrm{~m}$ below the ground surface. During drilling, dry clayey limestones were systematically observed down to depths of about 30m, which indicates that the Dogger aquifer is confined by this overlying lowpermeability unit. Two additional wells were drilled down to the crystalline rocks (about 160m depth), enabling pressure-head measurements in the lower and middle-Lias aquifer. Under natural conditions, the piezometric levels range from $30 \mathrm{~m}$ to $35 \mathrm{~m}$ below the ground surface. The pressure-head difference between the two aquifers suggests that these systems are well isolated from each other by the Toarcian marls. The Dogger aquifer can thus be considered as a fully confined aquifer. 
Extensive hydrogeophysical investigations have been made at the HES since 2002. The coupling between flowmeter and borehole imaging logs indicates that flowpaths in the Dogger aquifer are strongly constrained within subhorizontal karstic channels and subvertical fractures (Audouin et al., Flowpath structure in a limestone aquifer: multi-borehole logging investigations at the Hydrogeological Experimental Site of Poitiers, France. Accepted for publication in Hydrogeology Journal, (2007)). A program of slug testing has been carried out as a part of an extensive study of spatial variability in aquifer properties (see e.g. Bernard et al. 2006, Kaczmaryk and Delay 2007). The slug tests were performed after an important series of pumping tests, which ensured that each well was properly developed. Note that the piezometric levels in the lower and middle-lias have been continuoulsy monitored during pumping-test and slug-test experiments performed in the HES wells. Any pressure-head perturbation has never been observed in the lower and middle-Lias aquifer, which confirms the fully confined nature of the Dogger aquifer and removes any leakage assumption between the two systems.

Slug-test perturbations were initiated by sudden releases of water (falling-head initiation), using a $3 \mathrm{~m}^{3}$ capacity tank equipped with a rapid flow valve. Nine pressure transducers with $2 \mathrm{~Hz}$ frequency data loggers were used for each experiment, allowing the water level recovery in the slugged well and the cross-borehole head responses in 8 neighbouring wells to be monitored simultaneously. Depending on the location of the slugged well, distances to observation wells were either 50/70 m (square configuration) or 50/70/100/110/140 m (edge configuration). Following the recommendations by Zurbuchen et al. (2002) and Butler Jr. et al. (2003), the pressure transducers were placed within $0.5 \mathrm{~m}$ below the static level, which minimised the errors in measured heads caused by the acceleration of the water column. Resolution and estimated precision of head measurements were $10^{-3} \mathrm{~m}$ and $3 \times 10^{-3} \mathrm{~m}$, respectively. All slug test data

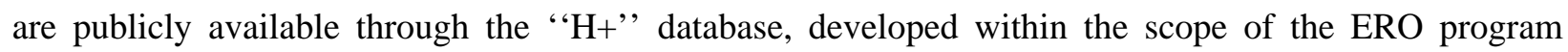
(French Environmental Research Observatory, http://hplus.ore.fr), see de Dreuzy et al. (2006). Fig. 6 shows the response curves of a slug test performed in well M19, with observation wells M16, M21, M22, MP6, MP7 and P1. Using the semi-analytical solution (17) and the automatic inversion procedure leads to a good fit of the underdamped response in well M19 with the following parameters: $n=1.99, K=5.9 \times 10^{-}$ ${ }^{4} \mathrm{~m} . \mathrm{s}^{-1}, \mathrm{Le}=137 \mathrm{~m}, S_{s}=1 \times 10^{-15} \mathrm{~m}^{-1}$. Recalling that aquifer flow dimension and storage have a low influence on the slugged well response (Barker 1988, McElwee et al. 1995a), the accuracy of the above $n$ 
and $S_{s}$ estimates is expected to be low. Other models can thus be used for interpreting the recovery curve in well M19. As an example, the model of McElwee and Zenner (1998) enables to make a reasonable (yet less accurate) fit with a $K$-value of $6.4 \times 10^{-4} \mathrm{~m} / \mathrm{s}$. Owing to this uncertainty, one of the main interests of our model is to allow more reliable estimates of aquifer parameters through the interpretation of crossborehole responses, which are more sensitive to $n$ and $K$. The observation wells monitored during the slug test in M19 show 3 types of responses: no perturbation in P1, a very small overdamped response in MP7 (a few millimeters), and underdamped responses in well M16, MP6, M21 and M22. One can notice that both time and amplitude of the first perturbation peak in cross-borehole responses do not depend on the distance $r_{L}$ to the slugged well. The response in M21, located 70m from M19, shows a maximum peak amplitude of $0.19 \mathrm{~m}$ at $9.5 \mathrm{~s}$ while the response in well M22, located 50m from M19, shows a maximum peak amplitude of $0.1 \mathrm{~m}$ at $13 \mathrm{~s}$. Oscillation period lengths also differ among observation wells, from 22s in M21 to 32s in MP6. All the cross-borelohe slug test data collected from HES have been interpreted using the semi-analytical solution (31) and the automatic inversion procedure described above. Table 1 summarizes the sets of parameters $n, K, S_{s}, L e$, and $L e_{o}$ stemming from these interpretations with their respective errors. The relative precision of parameter estimates is consistent with the sensitivity analysis result. The flow dimension $n$ is the most accurately determined parameter, with a relative error ranging between 1 and 20\%. In most cases, its accuracy is within 10\%. The largest errors are related to high flow dimension and overdamped responses with weak amplitude, which causes the signal-to-noise ratio to be low. The relative error on hydraulic conductivity $K$ ranges between 5 and $50 \%$. Such accuracy may be perceived as very satisfying in light of the simplicity and rapidity of slug tests as compared to pumping tests. Errors on effective lengths depend on the type of response. For underdamped responses, the high sensitivity of $L e$ and $L e_{o}$ favours the estimation of these parameters and relative errors are generally less than $100 \%$, excepted where the two effective length values are very contrasted. As expected from the sensitivity analysis, the less accurate estimations are for Ss with error values ranging between 15 and $1600 \%$. These errors are significant but a first rough estimate of the order of magnitude of storage is provided. Note that different $n$ and $K$ estimates were obtained on the same well pairs when reversing slugged and observation wells, which is a common feature in heterogeneous aquifers (see e.g. Doe and Geier 1991). As illustrated in Fig. 7, the model is able to fit properly the various types of observed 
responses. Note the low-frequency oscillations in the underdamped response observed at well MP6 (Fig. 7d), which are well reproduced using a large effective length for this well (Leo $=331 \mathrm{~m})$. This large value is consistent with other slug test interpretations involving MP6 as slugged or observation well. The interest of fractional flow dimension modelling is illustrated by Fig. 8, which shows the best curve fits obtained for a standard underdamped response assuming either fractional $n$-value or $2 \mathrm{D}$ flow $(n=2)$. The main difficulty with 2D modelling is to reproduce the high attenuation between the first and second peaks as compared to that of the next ones. A better data fit is clearly obtained with the assumption of fractional flow dimension in the aquifer. Figure 9 shows the distribution of flow dimension and hydraulic conductivity values listed in Table 1. Flow dimension values range between 1.6 and 2.5, with a mean value of 2.15 and a standard deviation of 0.19 . Such variability in $n$-values has been reported by several authors for comparable field scale studies (Geier et al. 1995, Winberg 1996, Leveinen et al. 1998, Leborgne et al. 2004). According to (Dershowitz and Doe 1997), the distribution of flow dimensions may provide valuable information about heterogeneity and connectivity of flowpath networks. When building discrete flowpath network models, efforts must be made for achieving flow models consistent with the observed distribution of flow dimensions. Interpreted hydraulic conductivity values range between $4.4 \times 10^{-5}$ and $7.7 \times 10^{-4} \mathrm{~m} . \mathrm{s}^{-1}$, and exhibit a lognormal distribution with a modal value of approximately $2.0 \times 10^{-4} \mathrm{~m} . \mathrm{s}^{-1}$. In a previous interpretation of single-well slug tests performed at the HES, Audouin and Bodin (2006) obtained $K$-values ranging between $2.5 \times 10^{-6}$ and $6.4 \times 10^{-4} \mathrm{~m} . \mathrm{s}^{-1}$. While upper bound estimates are fairly similar for the two studies, the lower $K$-values obtained in the present analysis are significantly higher than those interpreted from single-well slug tests. This apparent truncation is consistent since head perturbations induced in low transmissivity wells are not likely to propagate a long distance from the slugged well. In heterogeneous aquifers, cross-borehole slug test interpretations are thus expected to yield hydrodynamic parameters characterizing well-connected flowpaths. As mentioned earlier, coupled borehole imaging and flowmeter measurements indicate that flowpaths in the HES aquifer are strongly constrained within subhorizontal karstic channels and subvertical fractures (Audouin et al., Flowpath structure in a limestone aquifer: multi-borehole logging investigations at the Hydrogeological Experimental Site of Poitiers, France. Accepted for publication in Hydrogeology Journal, 2007). The $n$-values and $K$-values from the present study are thus expected to reflect the 
hydraulic properties of this channelized flow network. The interpretation results of cross-borehole slug tests may also be compared to those of pumping tests performed at the HES since 2002 (Bernard et al. 2006). A particular feature is that typically shaped drawdown curves have been consistently monitored during HES pumping test experiments. These curves show an upward curvature when plotted versus the logarithm of time, which makes them uninterpretable with conventional models such as the one by Cooper and Jacob (1946). According to Delay et al. (2004), such upward curvature may be due to a fractal scaling of aquifer hydraulic properties. Pumping test interpretations made by Bernard et al. (2006) with the model of Delay et al. (2004) lead to $K$-values ranging between $2.1 \times 10^{-5} \mathrm{~m}^{2} \cdot \mathrm{s}^{-1}$ and $5.2 \times 10^{-5} \mathrm{~m}^{2} \cdot \mathrm{s}^{-1}$. Owing to the fractal model assumption, hydraulic conductivity is inherently scale- and time-dependent but the interpreted values tend to homogenize towards $K=3.5 \times 10^{-5} \mathrm{~m} \cdot \mathrm{s}^{-1}$ for scales over $100-150 \mathrm{~m}$. The $K$-values interpreted from pumping tests are thus approximately one order of magnitude lower than those interpreted from cross-borehole slug tests. This finding is consistent with the above assumption concerning the selectivity of slug test characterization. The underlying idea is that the head perturbation induced by a slug test propagates only through the flowpaths having the lowest hydraulic resistance. While pumping tests involve the whole fracture/karstic-channel/matrix system because of the limited storage capacity of karstic channels and fracture voids, slug tests focus precisely on preferential flowpath networks made by fractures and karstic channels. Hydraulic conductivities estimated from cross-borehole slug tests are consequently higher than those interpreted from pumping tests.

\section{Summary and conclusion}

A new model has been developped for the interpretation of cross-borehole slug tests in fractured rocks. It includes inertial effects at both test and observation wells and fractional flow dimension in the aquifer. The semi-analytical solutions have been developed in the Laplace domain and their practical use needs numerical Laplace inversion. This task can be easily performed using standard numerical routines such as that written by Hollenbeck (1998). For mathematical convenience, several simplifying assumptions have been used in the development of semi-analytical solutions (e.g. totally penetrating wells, no skin effect ...). The model can readily be extended to account for partially penetrating wells according to the Butler 
and Zhan (2004) approach, for skin effects according to Kipp (1985), and for nonlinear effects in the slugged well according to McElwee and Zenner (1998). Our model has 5 fitting parameters: flow dimension $n$, hydraulic conductivity $K$, specific storage coefficient $S$ s and effective lengths of test well $L e$ and of observation well $L e_{o}$. The sensitivity of the model to these parameters may be ranked as follows: $n$ $>K>L e \sim L e_{o}>$ Ss. The model developed has been coupled to an automatic inversion algorithm for facilitating the interpretation of real field data. This inversion algorithm is based on a Gauss-Newton optimization procedure conditioned by re-scaled sensitivities. The model has been used to interpret successfully cross-borehole slug test data from the Hydrogeological Experimental Site (HES) of Poitiers, France, consisting of fractured and karstic limestones. Further calculations of relative errors on parameter estimates show that accuracy on $n$ and $K$ is below $20 \%$ and that on $S$ s is about one order of magnitude. Of course, these results must be considered with caution because of uncertainty about the validity of certain model assumptions such as aquifer homogeneity and isotropy (Barker 1988). Nevertheless, the comparison of $K$-values estimated from slug tests with those interpreted from pumping test experiments suggests that cross-borehole slug tests are able to identify the hydrodynamic properties of karstic channels and fractures flowpaths. The underlying idea is that the head perturbation induced by a slug test propagates only through those flowpaths with the lowest hydraulic resistance. Slug tests may thus be considered as complementary to pumping tests, which more likely provide bulk properties of the whole fracture/karstic-channel/matrix system. Current work is done for analysing to which extent the $n, K$ and $S s$ values estimated by slug tests are relevant to constrain a discrete fracture network (DFN) model of the HES limestone aquifer (FRACMAN model, Dershowitz and Doe 1997). This work is carried out within a general framework attempting to confront different modelling approaches to the HES data (national scientific program MACH-1: "Modelling of Heterogeneous Carbonate Aquifers - 1. Flow Dynamics").

\section{Acknowledgements}

We are grateful to the "Poitou-Charentes Water Research Program" (XIIe CPER), and to the French national research programs MACH-1 ("Modelling of Heterogeneous Carbonate Aquifers - 1. Flow Dynamics"), ERO ("Environmental Research Observatory"), and HTHS ("Hydrodynamic and Transfers in Hydrogeological Systems") for their financial support to this work. 


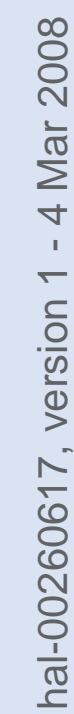




\section{References}

Audouin, O., and J. Bodin. 2007. Analysis of slug-tests with high-frequency oscillations. Journal of Hydrology 334 (1-2), 282-289. doi:10.1016/j.jhydrol.2006.10.009.

Barker, J. A. 1988. A generalized radial flow model for hydraulic tests in fractured rock. Water Resources Research 24 (10), 1796-1804.

Bernard, S., F. Delay, and G. Porel. 2006. A new method of data inversion for the identification of fractal characteristics and homogenization scale from hydraulic pumping tests in fractured aquifers. Journal of hydrology 328 (3-4), 647-658. doi:10.1016/j.jhydrol.2006.01.008

Butler Jr., J. J. 1997. The Design, Performance, and Analysis of Slug Tests. Lewis Publishers, 252p.

Butler Jr., J. J. 2002. A simple correction for slug tests in small-diameter wells. Ground Water 40 (3), 303-307. doi:10.1111/j.1745-6584.2002.tb02658.x.

Butler Jr., J. J., and X. Zhan. 2004. Hydraulic tests in highly permeable aquifers. Water Resources Research 40, W12402. doi:10.1029/2003/WR002998.

Chen, C.-S. 2006. An analytic data analysis method for oscillatory slug tests. Ground Water 44 (4), 604608. doi:10.1111/j.1745-6584.2006.00202.x.

Cooper Jr., H. H., J. D. Bredehoeft, and I. S. Papadopulos. 1967. Response of a Finite-Diameter Well to an Instantaneous Charge of Water. Water Resources Research 3 (1), 263-269.

Cooper Jr., H .H. and C.E. Jacob, 1946. A generalized graphical method for evaluating formation constants and summarizing well field history, Am. Geophys. Union Trans., vol. 27, 526-534.

de Dreuzy, J.-R., J. Bodin, H. Le Grand, P. Davy, D. Boulanger, A. Battais, O. Bour, P. Gouze, and G. Porel. 2006. General database for ground water site information. Ground Water 44 (5), 743-749. doi:10.1111/j.1745-6584.2006.00220.x

de Hoog, F. R., J. H. Knight, and A. N. Stokes. 1982. An improved method for numerical inversion of Laplace transforms. SIAM Journal on Scientific and Statistical Computing 3, 357-366.

Delay, F., A. Kaczmaryk, and P. Ackerer. 2007. Inversion of interference hydraulic pumping tests in both homogeneous and fractal dual media. Advances in Water Resources 30, 314-334. doi:10.1016/j.advwatres.2006.06.008

Dershowitz, W., and T. Doe. 1997. Analysis of heterogeneously connected rock masses by forward modeling of fractional dimension flow behavior. International Journal of Rock Mechanics \& Mining Sciences 34 (3-4). doi:10.1016/S1365-1609(97)00237-2.

Doe, T. W., and J. E. Geier. 1991. Interpretation of fracture system geometry using well test data. Swedish Nuclear Fuel and Waste Management report 91-03, Stockholm.

Geier, J., W. Dershowitz, P. Wallmann, and T. Doe. 1995. Discrete fracture modeling of in-situ hydrologic and tracer experiments in fractured and jointed rock masses. Pages 511-518 in L. R. Myer and C. F. Tsang, editors. Proceedings of the Fractured and Jointed Rock Masses, Lake Tahoe, California.

Hollenbeck, K. J. 1998. INVLAP.M: A matlab function for numerical inversion of Laplace transforms by the de Hoog algorithm. http://www.isva.dtu.dk/staff/karl/invlap.htm.

Hvorslev, M. J. 1951. Time lag and soil permeability in ground-water observations. US Army Corps of Engineers, Waterways Experiment Station, Vicksburg, MS. Bulletin 36.

Kabala, Z. J. 2001. Sensitivity analysis of a pumping test on a well with wellbore storage and skin. Advances in Water Resources 24 (5) ,483-504. doi:10.1016/S0309-1708(00)00051-8.

Kaczmaryk, A., and F. Delay. 2007. Interference pumping tests in a fractured limestone (Poitiers France) : Inversion of data by means of dual-medium approaches. Journal of Hydrology 337 (12), 133-146. doi:10.1016/j.jhydrol.2007.01.025.

Karasaki, K., J. C. S. Long, and P. A. Witherspoon. 1988. Analytical models of slug tests. Water Resources Research 24 (1), 115-126.

Kipp Jr., K. L. 1985. Type curve analysis of inertial effects in the response of a well to a slug test. Water Resources Research 21 (9), 1397-1408.

Kuusela-Lahtinen, A., A. Niemi, and A. Luukkonen. 2003. Flow dimension as an indicator of hydraulic behavior in site characterization of fractured rock. Ground Water 41 (3), 333-341. doi:10.1111/j.1745-6584.2003.tb02602.x. 
Le Borgne, T., O. Bour, J.-R. De Dreuzy, P. Davy, and F. Touchard. 2004. Equivalent mean flow models for fractured aquifers : insights from a pumping tests scaling interpretation. Water Resources Research 40, W03512. doi:10.1029/2003WR002436.

Lee, J.-Y., and K.-K. Lee. 1999. Analysis of the Quality of Parameter Estimates form Repeated Pumping and Slug Tests in a Fractured Porous aquifer System in Wonju, Korea. Ground Water 37 (5), 699700. doi:10.1111/j.1745-6584.1999.tb01161.x.

Leveinen, J. 2000. Composite model with fractional flow dimensions for well test analysis in fractured rocks. Journal of Hydrology 234 (3-4), 116-141. doi:10.1016/S0022-1694(00)00254-7.

Leveinen, J., E. Rönkä, J. Tikkanen, and E. Karro. 1998. Fractional flow dimensions and hydraulic properties of a fracture-zone aquifer, Leppävirta, Finland. Hydrogeology Journal 6 (3), 327-340. doi:10.1007/s100400050156.

McElwee, C. D., G. C. Bohling, and J. J. Butler Jr. 1995a. Sensitivity Analysis of Slug Tests. Part 1. The Slugged Well. Journal of Hydrology 164 (1), 53-67. doi:10.1016/0022-1694(94)02568-V.

McElwee, C. D., J. J. Butler Jr., G. C. Bohling, and W. Liu. 1995b. Sensitivity Analysis of Slug Tests. Part 2. Observation Wells. Journal of Hydrology 164 (1), 69-87. doi:10.1016/01489062(95)99086-D.

McElwee, C. D., and M. A. Zenner. 1998. A Nonlinear Model for Analysis of Slug-Test data. Water Resources Research 34 (1), 55-66. doi:10.1029/97WR02710.

Nocedal, J. and Wright, S. J. 1999, Numerical Optimization, Springer-Verlag Telos, Berlin.

Novakowski, K. S. 1989. Analysis of pulse interference tests. Water Resources Research 25 (11), 2377.

Novakowski, K. S., and G. S. Bickerton. 1997. Borehole measurement of the hydraulic properties of lowpermeability rock. Water Resources Research 33 (11), 2509-2517. doi:10.1029/97WR02189.

Tsang, C.-F., and I. Neretnieks. 1998. Flow channeling in heterogeneous fractured rocks. Reviews of Geophysics 36 (2), 275-298. doi: 10.1029/97RG03319.

Van Der Kamp, G. 1976. Determining Aquifer Transmissivity by Means of Well Response Tests : The Underdamped Case. Water Resources Research 12 (1), 71-77.

Walker, D. D., and R. M. Roberts. 2003. Flow dimensions corresponding to hydrogeologic conditions. Water Resources Research 39 (12), 1349. doi: 10.1029/2002WR001511.

Winberg, A. 1996. First TRUE stage - Tracer Retention Understanding Experiments. Descriptive structural-hydraulic models on block and detailed scales of the TRUE-1 site. ICR 96-04, SKB, Stockholm.

Yeh, H.-D., and S.-Y. Yang. 2006. A novel analytical solution for a slug test conducted in a well with a finite-thickness skin. Advances in Water Resources 29 (10), 1479-1489. doi: 10.1016/j.advwatres.2005.11.002.

Zhan, X., and J. J. Butler Jr. 2003. Mathematical derivations of semianalytical solutions for hydraulic tests in highly permeable aquifers. Kansas geological survey open-file report 2003-60, Lawrence.

Zlotnik, V. A., and V. L. McGuire. 1998a. Multi-level slug tests in highly permeable formations: 1. modification of the Springer-Gelhar (SG) model. Journal of Hydrology 204 (1), 271-282. doi: 10.1016/S0022-1694(97)00128-5.

Zlotnik, V. A., and V. L. McGuire. 1998b. Multi-level slug tests in highly permeable formations: 2. hydraulic conductivity identification, method verification, and field applications. Journal of Hydrology 204 (1), 283-296. doi: 10.1016/S0022-1694(97)00127-3.

Zurbuchen, B. R., V. A. Zlotnik, and J. J. Butler Jr. 2002. Dynamic interpretation of Slug tests in highly permeable aquifers. Water Resources Research 38 (3), 1025. doi: 10.1029/2001WR000354. 


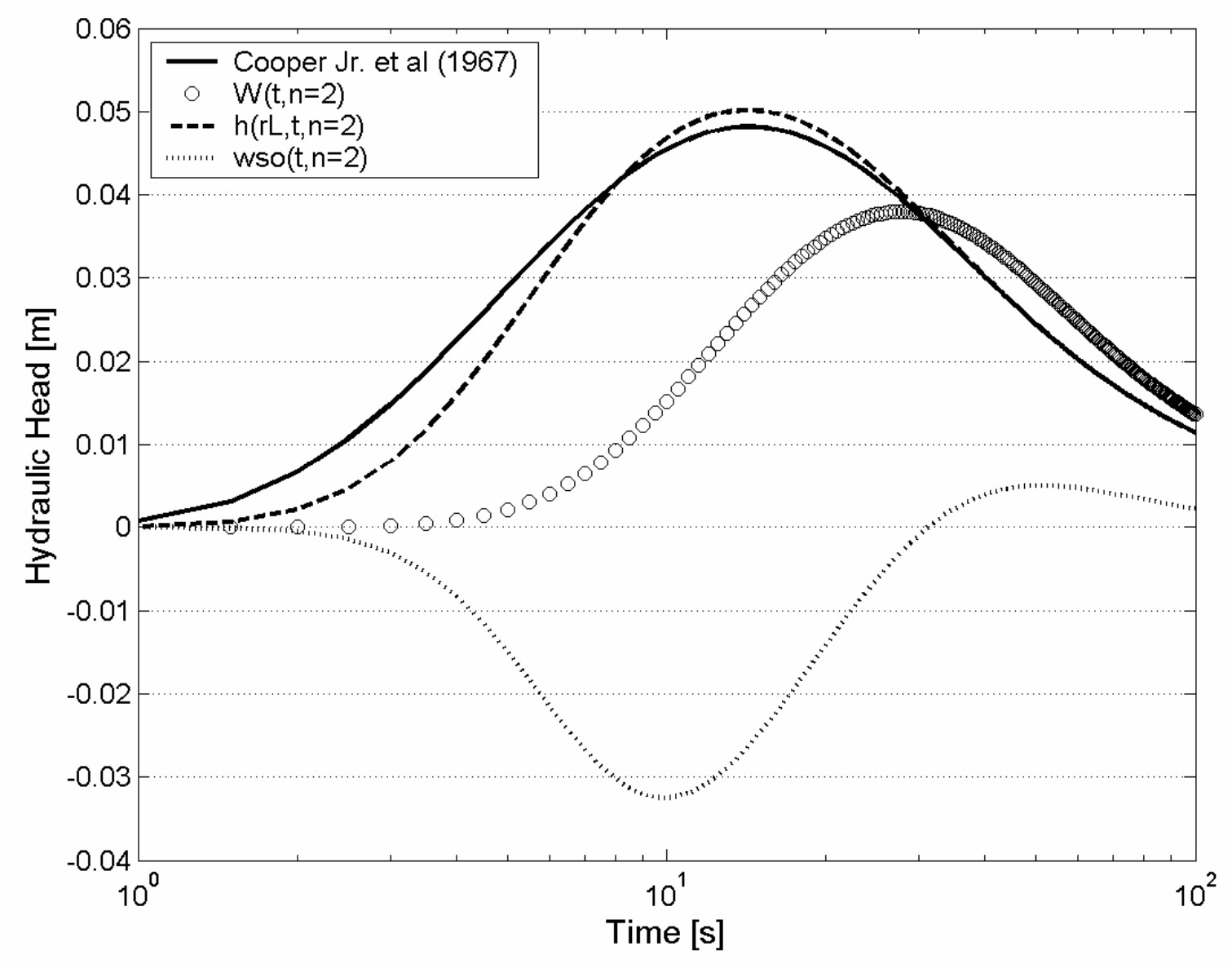

Fig. 1: Comparison of cross-borehole slug test responses with $[\mathrm{A}]$ no inertial effects (Cooper Jr. et al. 1967) ; [B] inertial effects in the test well: $h\left(r_{L}, t\right)$ - Eq. 20 ; [C] inertial effects in both the test well and observation well $W(t, n=2)$ - Eq. 31 ; [D] deviation of hydraulic head within the screen of the observation well $w_{s o}(\mathrm{t}, \mathrm{n}=2)$ - Eq. 30 


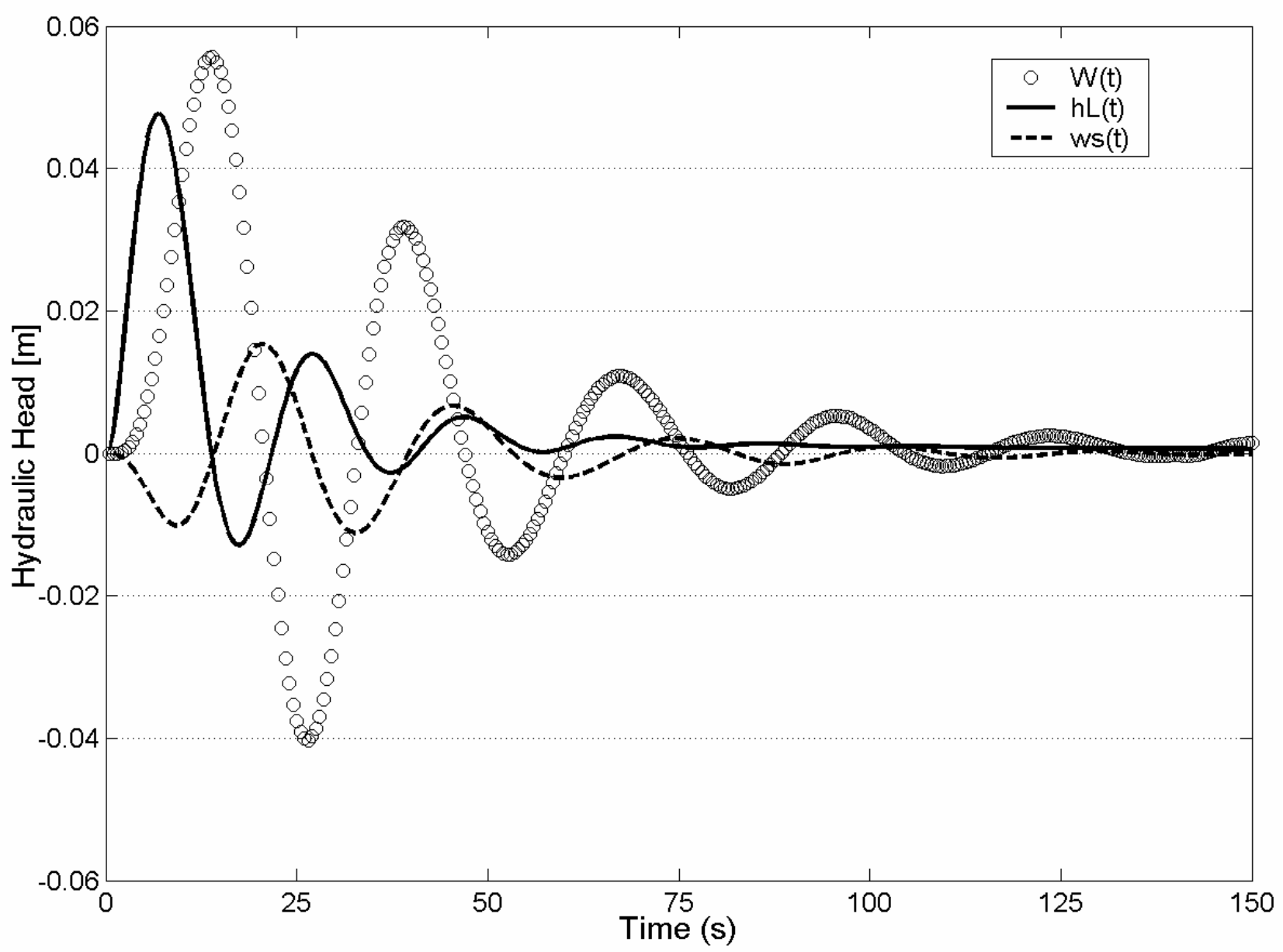

Fig. 2: (a) Deviation of hydraulic head $\mathrm{W}(\mathrm{t}), \mathrm{h}_{\mathrm{L}}(\mathrm{t})$ and $\mathrm{w}_{\mathrm{s}}(\mathrm{t})$ curves $\left(\mathrm{Kr}=3 \times 10^{-5} \mathrm{~m} \cdot \mathrm{s}^{-1}, \mathrm{Ss}=5 \times 10^{-7} \mathrm{~m}^{-1}\right.$, $\mathrm{r}_{\mathrm{L}}=30 \mathrm{~m}, \mathrm{H}_{0}=1 \mathrm{~m}, \mathrm{Le}=\mathrm{Leo}=50 \mathrm{~m}, \mathrm{~b}=\mathrm{b}_{0}=100 \mathrm{~m}, \mathrm{r}_{\mathrm{c}}=\mathrm{r}_{\mathrm{co}}=\mathrm{r}_{\mathrm{s}}=\mathrm{r}_{\mathrm{so}}=0.11 \mathrm{~m}, \mathrm{n}=2$ ). (b) Deviation of hydraulic head $\mathrm{W}(\mathrm{t}), \mathrm{h}_{\mathrm{L}}(\mathrm{t})$ and $\mathrm{w}_{\mathrm{s}}(\mathrm{t})$ type curves $\left(\mathrm{Kr}=3 \times 10^{-4} \mathrm{~m} \cdot \mathrm{s}^{-1}, \mathrm{Ss}=5 \times 10^{-7} \mathrm{~m}^{-1}, \mathrm{r}_{\mathrm{L}}=30 \mathrm{~m}, \mathrm{H}_{0}=1 \mathrm{~m}\right.$, $\left.\mathrm{Le}=\mathrm{Leo}=50 \mathrm{~m}, \mathrm{~b}=\mathrm{b}_{0}=100 \mathrm{~m}, \mathrm{r}_{\mathrm{c}}=\mathrm{r}_{\mathrm{co}}=\mathrm{r}_{\mathrm{s}}=\mathrm{r}_{\mathrm{so}}=0.11 \mathrm{~m}, \mathrm{n}=2\right)$. 


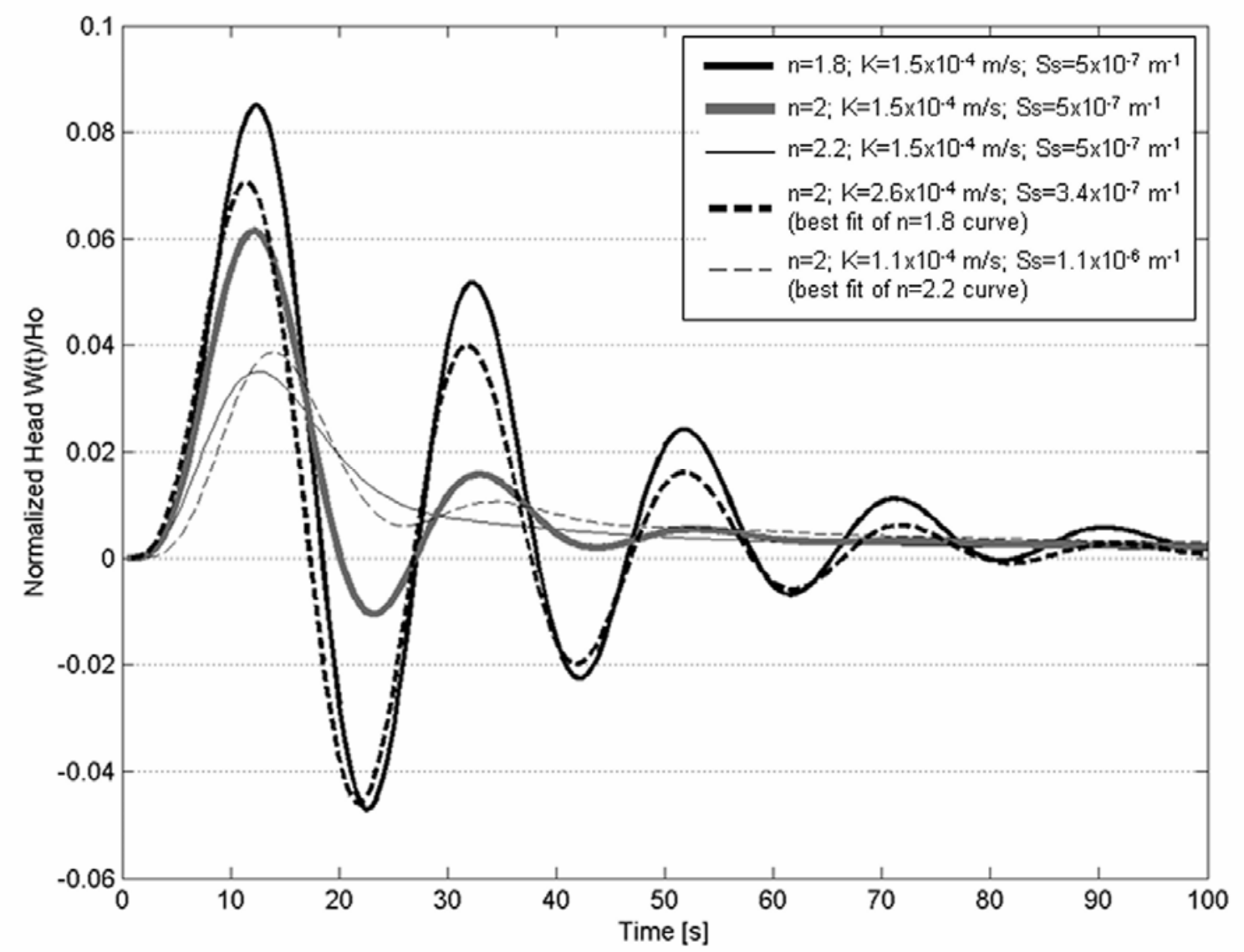

Fig. 3: Deviation of hydraulic head $\mathrm{W}(\mathrm{t})$ curves as a function of $\mathrm{n}\left(\mathrm{Kr}=1.5 \times 10^{-4} \mathrm{~m} \cdot \mathrm{s}^{-1}, \mathrm{Ss}=5 \times 10^{-7} \mathrm{~m}^{-1}\right.$, $\left.\mathrm{r}_{\mathrm{L}}=30 \mathrm{~m}, \mathrm{H}_{0}=1 \mathrm{~m}, \mathrm{Le}=\mathrm{Leo}=50 \mathrm{~m}, \mathrm{~b}=\mathrm{b}_{0}=100 \mathrm{~m}, \mathrm{r}_{\mathrm{c}}=\mathrm{r}_{\mathrm{co}}=\mathrm{r}_{\mathrm{s}}=\mathrm{r}_{\mathrm{so}}=0.11 \mathrm{~m}\right)$. 

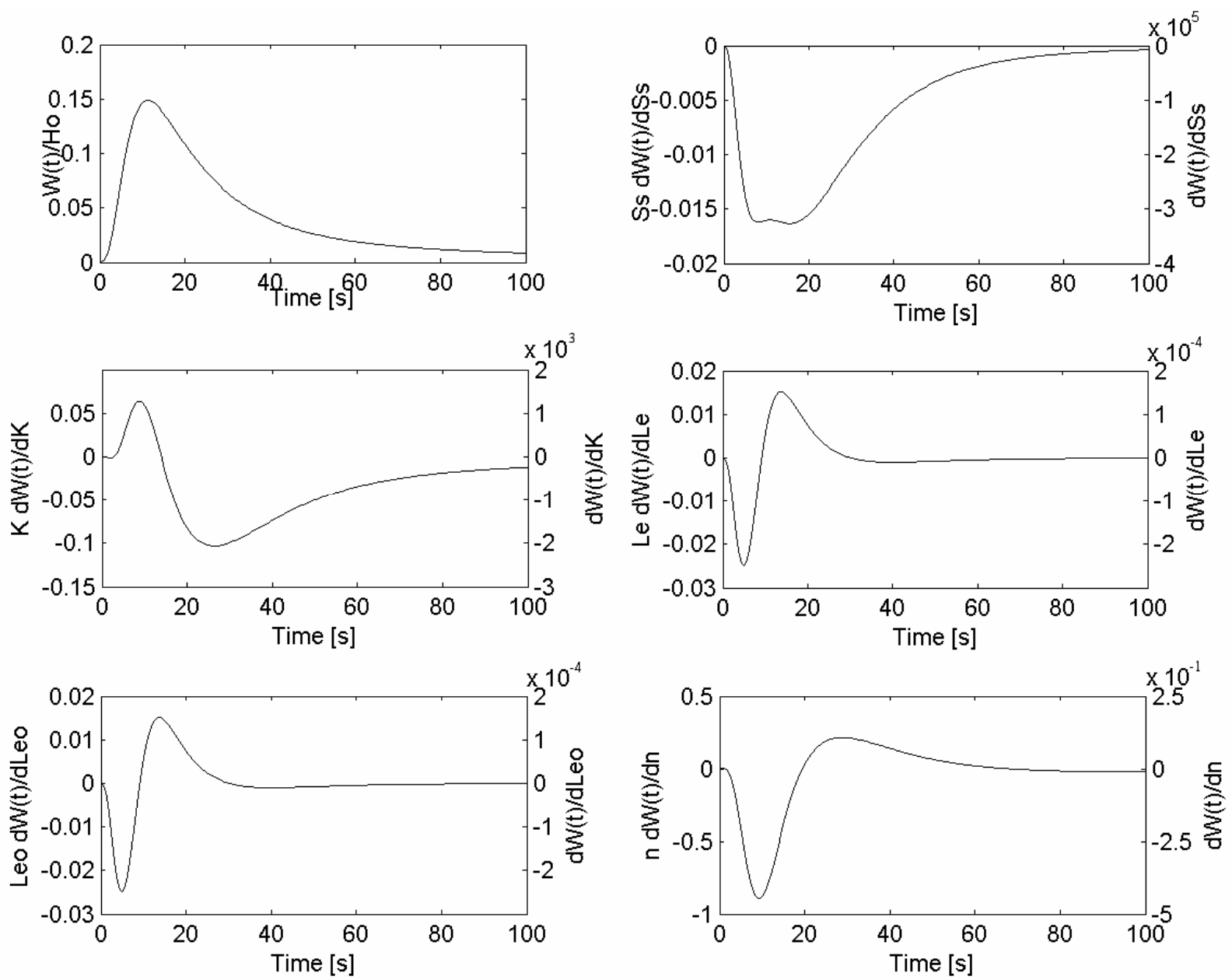

Fig. 4: Sensitivity curves to $\mathrm{Kr}$, Ss, Le, Leo and $\mathrm{n}$ for an overdamped hydraulic head $\mathrm{W}(\mathrm{t})\left(\mathrm{Kr}=5 \times 10^{-5} \mathrm{~m} . \mathrm{s}^{-}\right.$ $\left.{ }^{1}, \mathrm{Ss}=5 \times 10^{-8} \mathrm{~m}^{-1}, \mathrm{r}_{\mathrm{L}}=30 \mathrm{~m}, \mathrm{H}_{0}=1 \mathrm{~m}, \mathrm{Le}=\mathrm{Leo}=50 \mathrm{~m}, \mathrm{~b}=\mathrm{b}_{0}=100 \mathrm{~m}, \mathrm{r}_{\mathrm{c}}=\mathrm{r}_{\mathrm{co}}=\mathrm{r}_{\mathrm{s}}=\mathrm{r}_{\mathrm{so}}=0.11 \mathrm{~m}\right)$. 

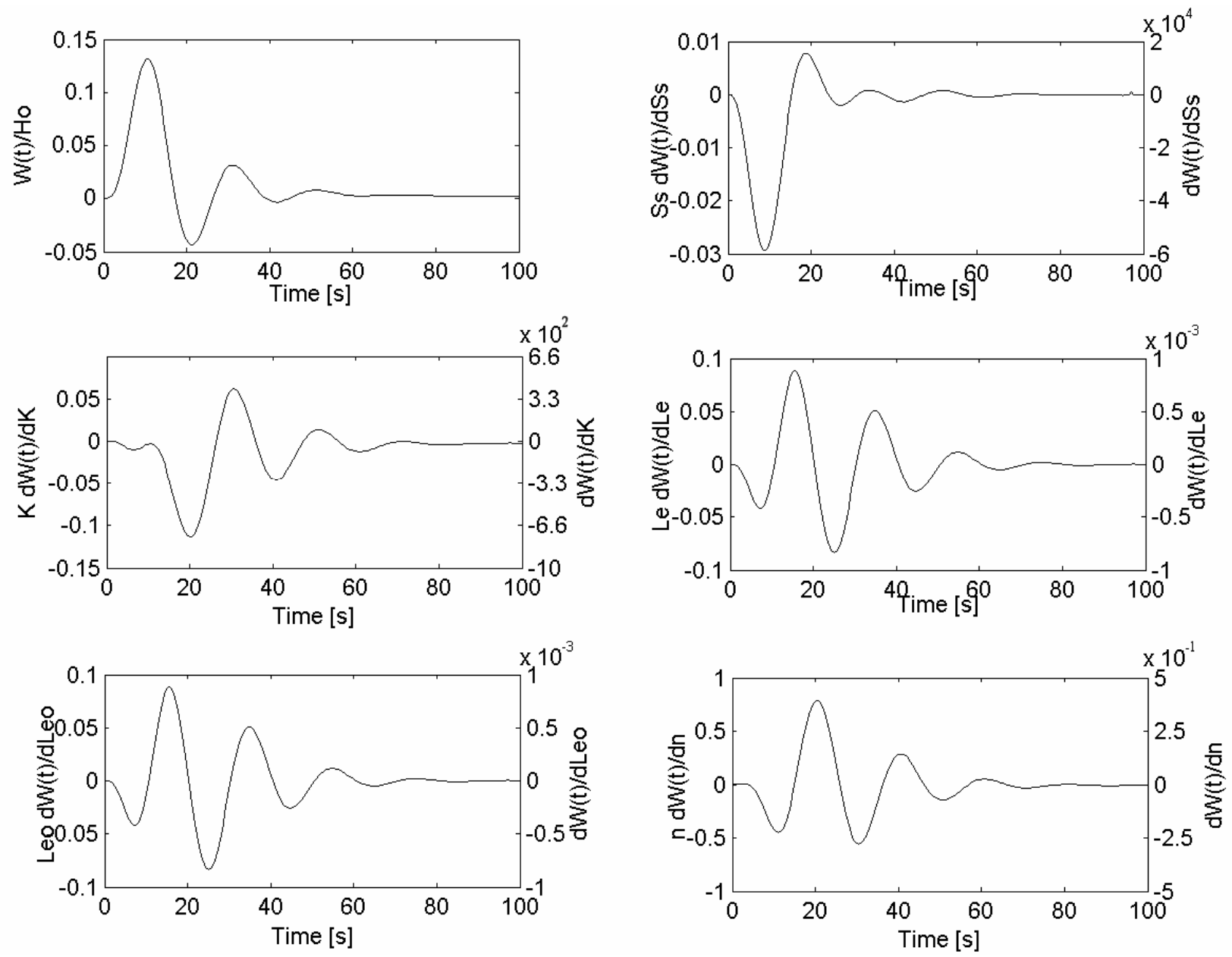

Fig. 5: Sensitivity curves to Kr, Ss, Le, Leo and $n$ for an underdamped hydraulic head $\mathrm{W}(\mathrm{t})\left(\mathrm{Kr}=1.5 \times 10^{-}\right.$ $\left.{ }^{4} \mathrm{~m} \cdot \mathrm{s}^{-1}, \mathrm{Ss}=5 \times 10^{-7} \mathrm{~m}^{-1}, \mathrm{r}_{\mathrm{L}}=30 \mathrm{~m}, \mathrm{H}_{0}=1 \mathrm{~m}, \mathrm{Le}=\mathrm{Leo}=50 \mathrm{~m}, \mathrm{~b}=\mathrm{b}_{0}=100 \mathrm{~m}, \mathrm{r}_{\mathrm{c}}=\mathrm{r}_{\mathrm{co}}=\mathrm{r}_{\mathrm{s}}=\mathrm{r}_{\mathrm{so}}=0.11 \mathrm{~m}\right)$. 


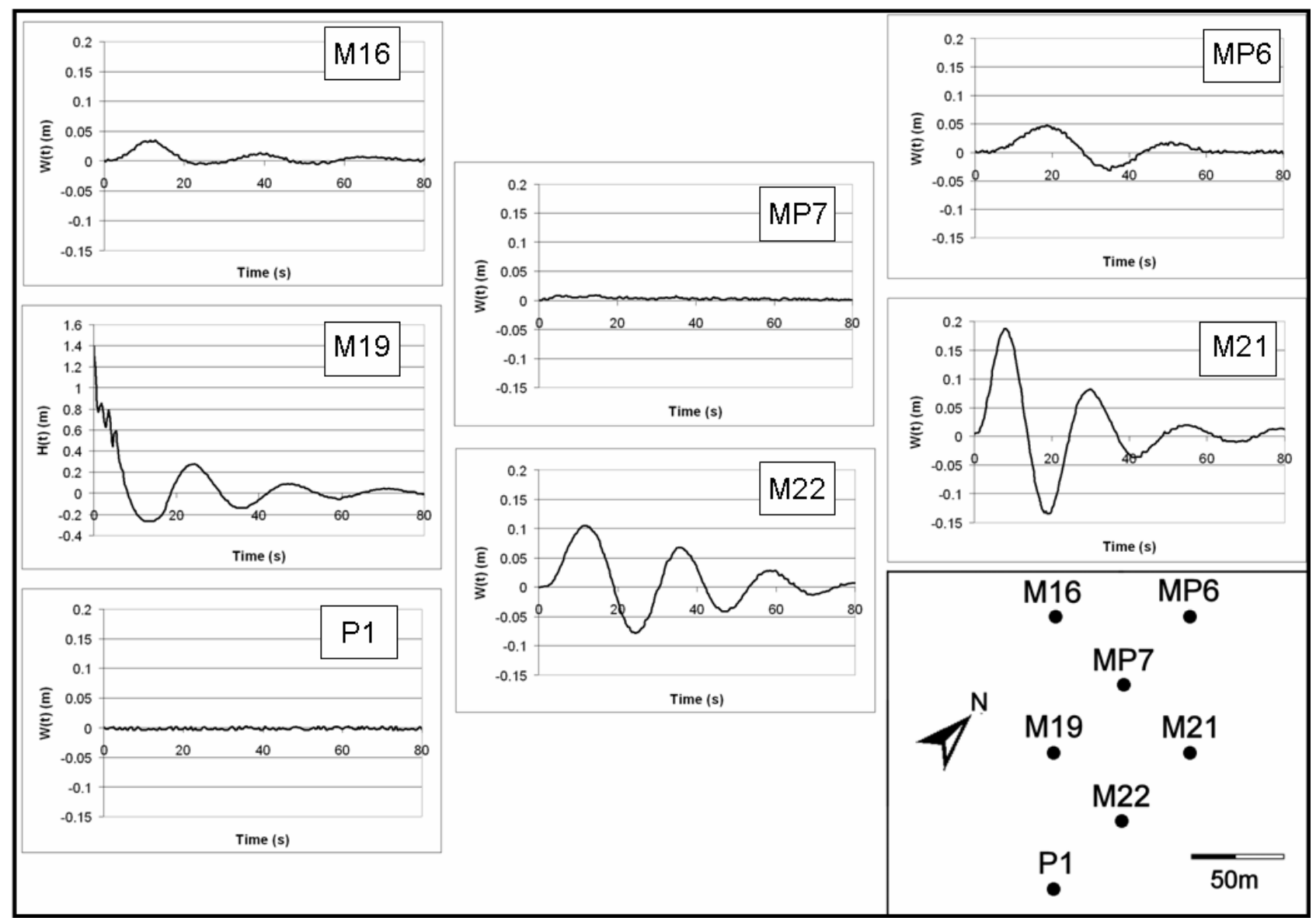

Fig. 6: Deviation of hydraulic head at wells M12, M21, M22, MP6, MP7 and P1 for a slug test initiated in the well M19. 
(A) Slug Test M19-M21

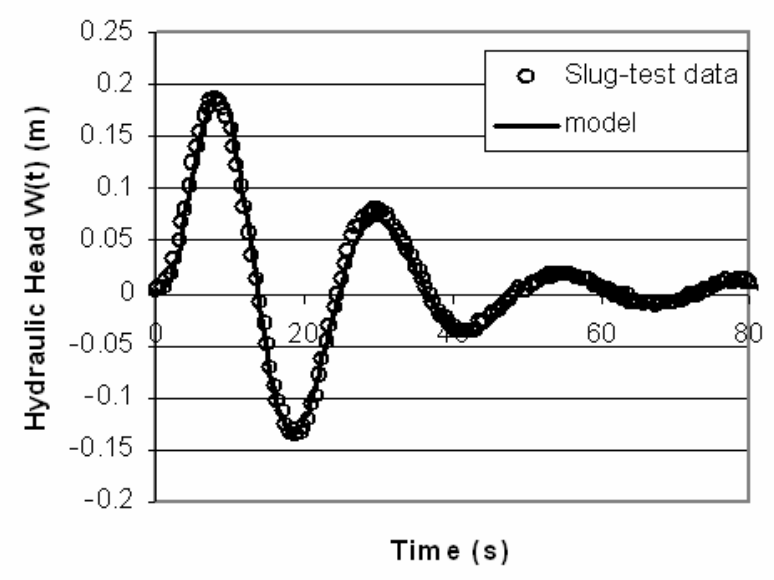

(C) Slug Test M05-M16

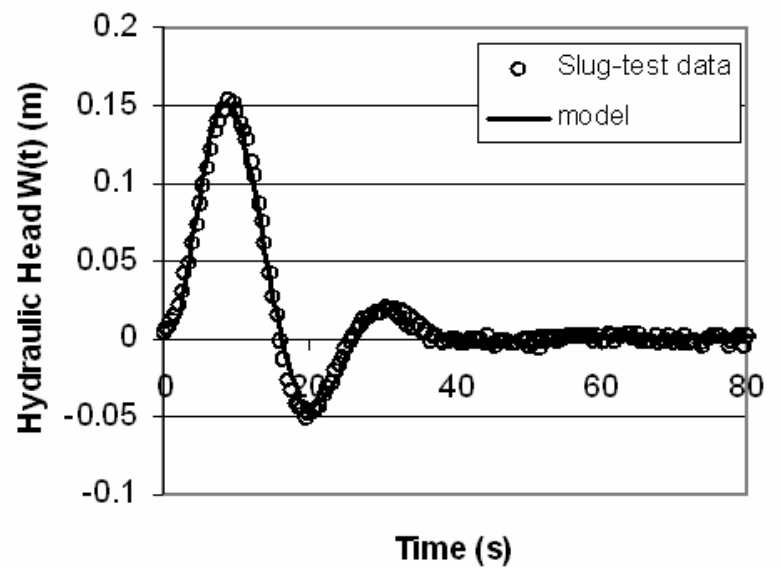

(B) Slug Test M03-M04

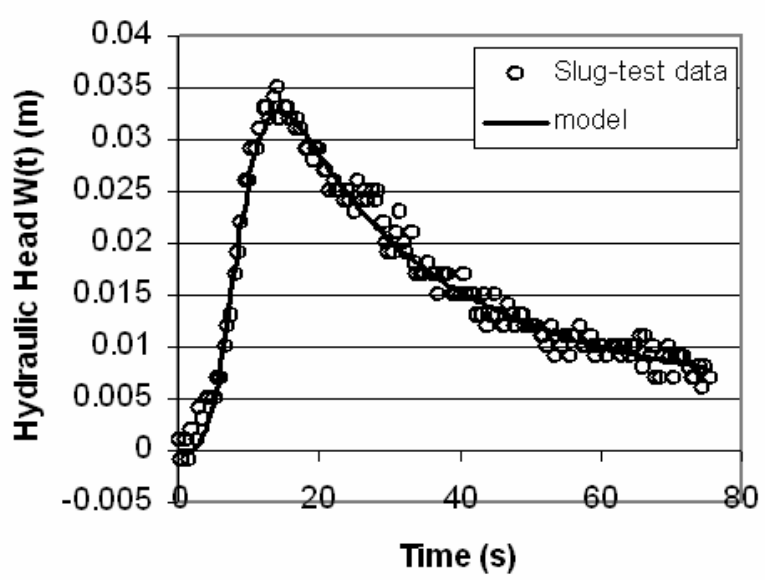

(D) Slug Test M16-MP6

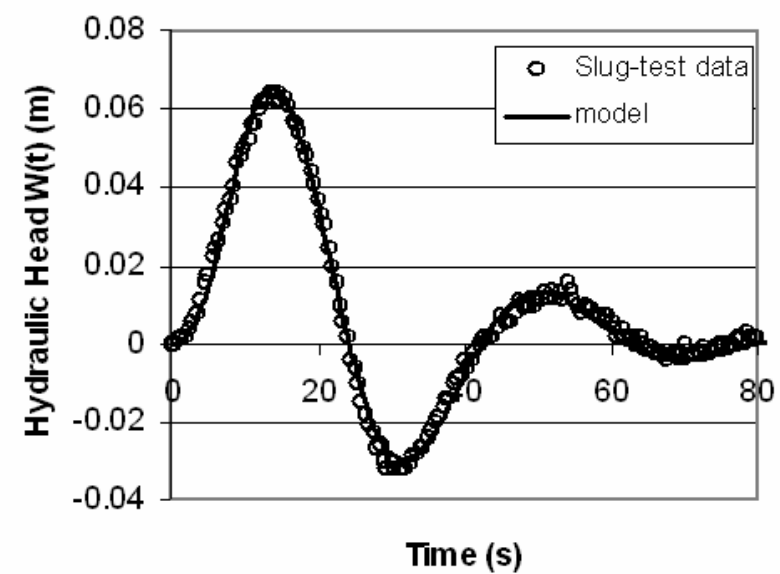

Fig. 7: Examples of interpretation of typical HES cross-borehole slug test data. Model parameters for the slug test M19-M21 (Fig. 7a: M19 = slugged well, M21 = observation well): $n=2.06, K=$ $6 \times 10^{-4} \mathrm{~m} \cdot \mathrm{s}^{-1}, \mathrm{Le}=40 \mathrm{~m}$, Leo $=129 \mathrm{~m}, S_{\mathrm{s}}=3 \times 10^{-10} \mathrm{~m}^{-1}$; slug-test M03-M04 (Fig. 7b): $n=1.97, K=$ $9.8 \times 10^{-5} \mathrm{~m} . \mathrm{s}^{-1}, \mathrm{Le}=69$, Leo $=53, S_{\mathrm{s}}=3.3 \times 10^{-7} \mathrm{~m}^{-1}$; slug-test M05-M16 (Fig. 7c): $n=1.96, K=$ $2.7 \times 10^{-4} \mathrm{~m} . \mathrm{s}^{-1}, L e=34 \mathrm{~m}$, Leo $=182 \mathrm{~m}, S_{\mathrm{s}}=1.7 \times 10^{-9} \mathrm{~m}^{-1}$; slug-test M16-MP6 (Fig. 7d): $n=2.35$, $K=4.4 \times 10^{-4} \mathrm{~m} \cdot \mathrm{s}^{-1}, L e=140 \mathrm{~m}$, Leo $=320 \mathrm{~m}, S_{\mathrm{s}}=1.5 \times 10^{-10} \mathrm{~m}^{-1}$. 


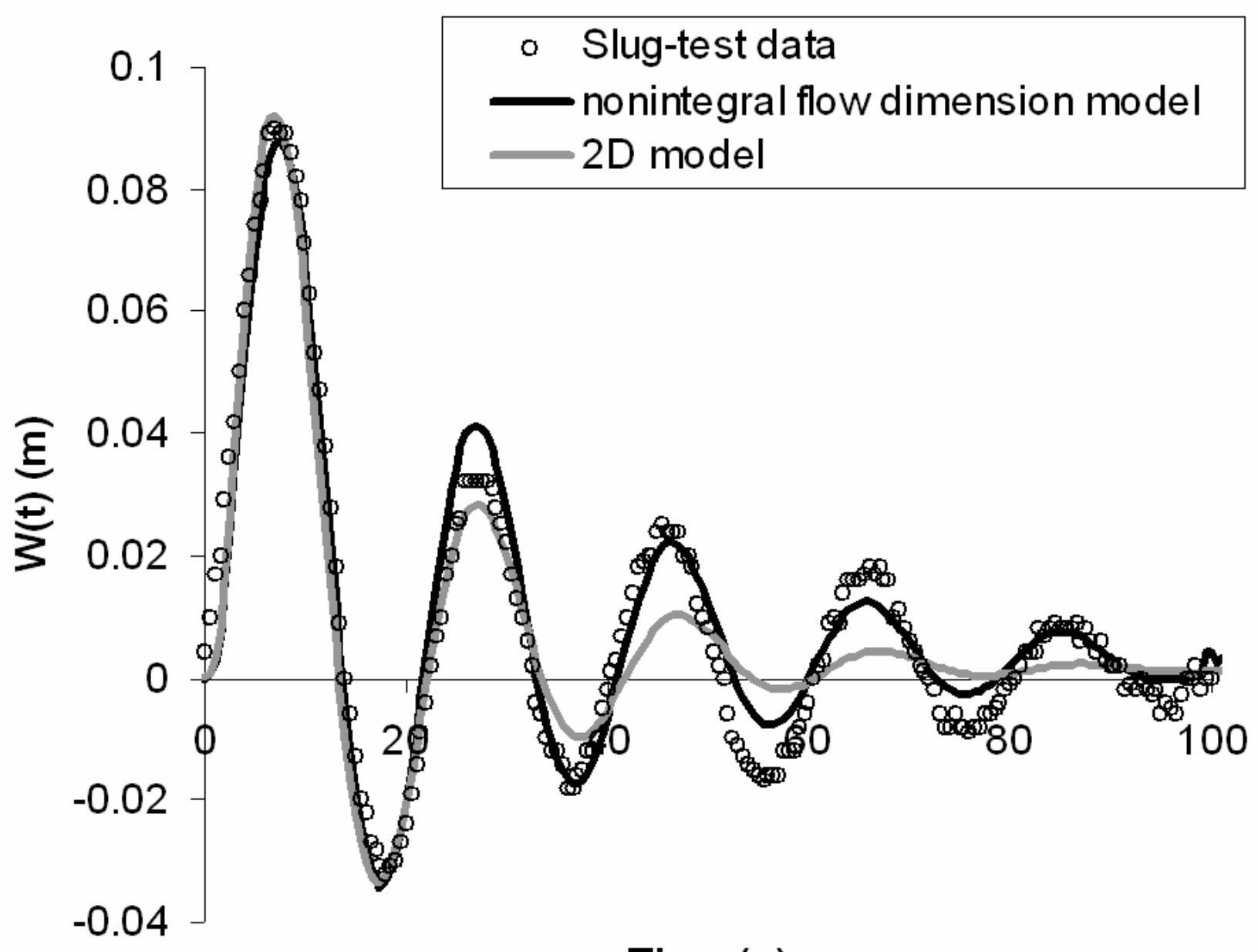

Time (s)

Fig. 8: Model fitting of cross-borehole slug test data M02-M13 (interdistance $=119 \mathrm{~m}$ ). Best fit model parameters: $n=1.75, K=6.2 \times 10^{-4} \mathrm{~m} \cdot \mathrm{s}^{-1}, S_{\mathrm{s}}=4.1 \times 10^{-8} \mathrm{~s}^{-1}, L e=98$, Leo $=5$ (nonintegral flow dimension model); $K=4.2 \times 10^{-4} \mathrm{~m} \cdot \mathrm{s}^{-1}, S_{s}=1.4 \times 10^{-8} \mathrm{~s}^{-1}, L e=98, L e o=5$ (2D model). 

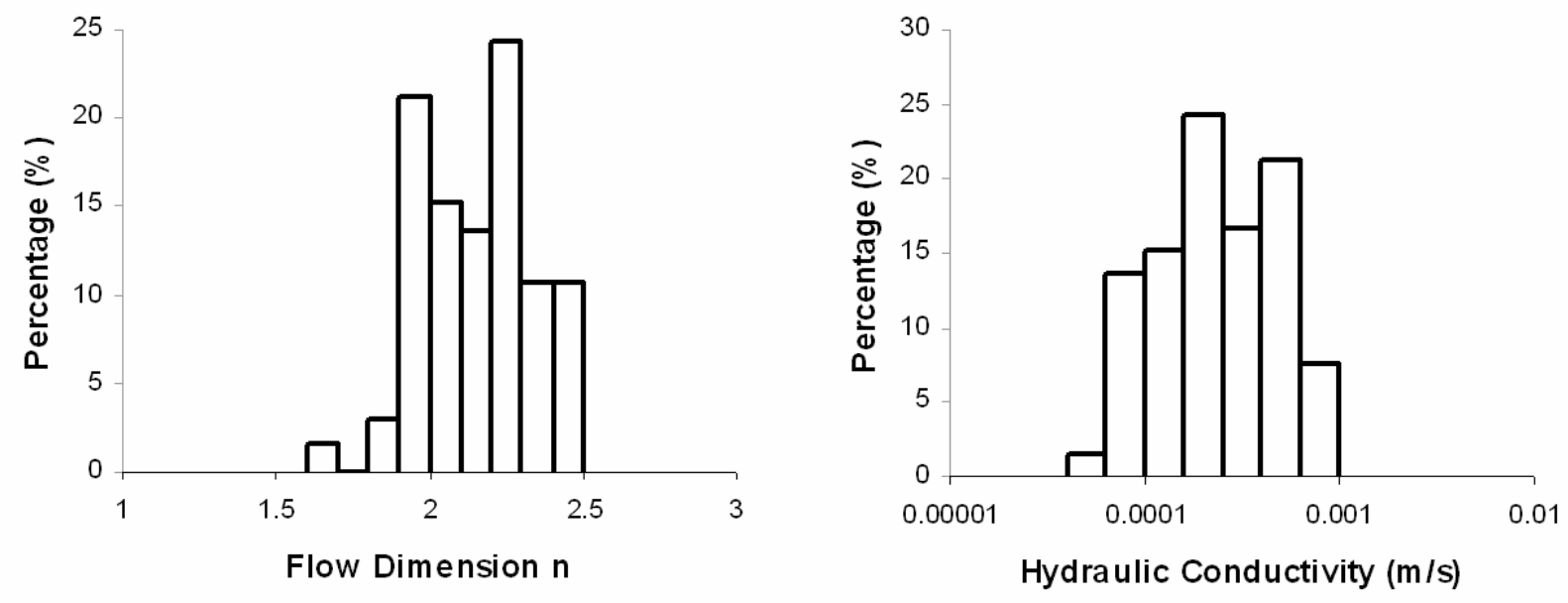

Fig. 9: Distribution of flow dimension and hydraulic conductivity, Hydrogeological Experimental Site, France 


\begin{tabular}{|c|c|c|c|c|c|c|c|c|c|c|c|}
\hline $\begin{array}{l}\text { Test } \\
\text { Well }\end{array}$ & $\begin{array}{c}\text { Observation } \\
\text { Well }\end{array}$ & $S s\left[m^{-1}\right]$ & $K\left[\mathrm{~m} \cdot \mathrm{s}^{-1}\right]$ & Le $[\mathrm{m}]$ & $\operatorname{Le}_{0}[\mathrm{~m}]$ & $n[-]$ & $\varepsilon_{S s}[\%]$ & $\varepsilon_{K}[\%]$ & $\varepsilon_{\text {Le }}[\%]$ & $\varepsilon_{\text {Leo }}[\%]$ & $\varepsilon_{n}[\%]$ \\
\hline M02 & M13 & 4.1E-08 & 4.5E-04 & 98 & 5 & 1.75 & 51 & 13 & 5 & - & 6 \\
\hline M02 & M19 & 2.4E-12 & 1.6E-04 & 141 & 21 & 1.93 & 838 & 34 & 3 & 161 & 7 \\
\hline $\mathrm{MO2}$ & M21 & 7.5E-08 & 1.0E-04 & 74 & 20 & 1.88 & 237 & 38 & 7 & - & 10 \\
\hline M02 & MP6 & 9.6E-09 & 5.0E-04 & 5 & 345 & 2.37 & 245 & 26 & - & 120 & 14 \\
\hline M03 & M04 & 3.3E-07 & 9.8E-05 & 69 & 53 & 1.97 & 30 & 6 & 436 & 424 & 5 \\
\hline M03 & M06 & 2.0E-07 & 1.0E-04 & 50 & 50 & 2.17 & 110 & 13 & - & - & 7 \\
\hline M03 & M07 & 2.0E-07 & 1.3E-04 & 100 & 100 & 2.27 & 137 & 15 & - & - & 10 \\
\hline M03 & M11 & 7.3E-08 & 1.1E-04 & 70 & 55 & 2.01 & 67 & 9 & - & - & 5 \\
\hline M03 & MP5 & 3.5E-07 & 1.5E-04 & 70 & 55 & 2.08 & 57 & 14 & - & - & 9 \\
\hline MO4 & M03 & 1.1E-07 & 1.1E-04 & 112 & 100 & 2.12 & 58 & 10 & 54 & - & 4 \\
\hline MO4 & M06 & 1.1E-08 & 1.8E-04 & 5 & 91 & 1.97 & 118 & 14 & - & 13 & 4 \\
\hline MO4 & M07 & 2.7E-08 & 4.1E-04 & 112 & 30 & 1.92 & 142 & 27 & 8 & 41 & 9 \\
\hline MO4 & M11 & 7.7E-09 & 1.7E-04 & 71 & 130 & 2.03 & 143 & 13 & 101 & 41 & 6 \\
\hline MO4 & MP4 & 4.6E-07 & 2.0E-04 & 285 & 168 & 2.24 & 107 & 24 & 122 & 256 & 11 \\
\hline MO4 & MP5 & 2.8E-08 & 3.7E-04 & 142 & 33 & 2.06 & 169 & 25 & 8 & 49 & 7 \\
\hline M04 & MP6 & 3.9E-07 & 2.3E-04 & 247 & 316 & 2.33 & 95 & 21 & 482 & 335 & 5 \\
\hline M05 & M04 & 1.5E-08 & 9.8E-05 & 103 & 318 & 2.31 & 295 & 23 & 50 & 45 & 9 \\
\hline M05 & M16 & 1.7E-09 & 2.7E-04 & 35 & 183 & 1.96 & 284 & 23 & 35 & 11 & 8 \\
\hline M05 & M19 & 9.4E-09 & 2.2E-04 & 168 & 196 & 2.08 & 185 & 36 & 40 & 92 & 7 \\
\hline M05 & MP5 & 3.9E-09 & 1.6E-04 & 129 & 417 & 2.33 & 1145 & 47 & 393 & 114 & 18 \\
\hline M05 & MP6 & 9.8E-09 & 1.6E-04 & 212 & 323 & 2.14 & 157 & 21 & 48 & 42 & 5 \\
\hline M06 & M03 & $8.4 \mathrm{E}-08$ & 5.5E-05 & 127 & 220 & 1.88 & 54 & 11 & 20 & 17 & 6 \\
\hline M06 & M04 & 8.1E-09 & 8.9E-05 & 91 & 76 & 1.92 & 119 & 16 & 64 & 126 & 5 \\
\hline M06 & M07 & 1.7E-07 & 8.3E-05 & 104 & 37 & 1.99 & 64 & 17 & 58 & 295 & 7 \\
\hline M06 & M11 & 2.1E-09 & 9.2E-05 & 121 & 74 & 1.91 & 163 & 15 & 33 & 89 & 5 \\
\hline M07 & M04 & 1.9E-09 & 5.8E-04 & 110 & 36 & 2.36 & 283 & 23 & 11 & 76 & 3 \\
\hline M07 & M11 & 2.7E-07 & 3.9E-04 & 119 & 150 & 2.43 & 104 & 23 & 38 & 40 & 4 \\
\hline M07 & MP5 & 1.0E-12 & 5.0E-04 & 95 & 13 & 2.22 & - & 15 & 6 & 114 & 1 \\
\hline M07 & MP6 & 1.0E-07 & 2.7E-04 & 205 & 110 & 2.46 & 99 & 17 & 25 & 32 & 3 \\
\hline M11 & M03 & 5.9E-09 & 1.3E-04 & 100 & 136 & 2.28 & 162 & 7 & - & 48 & 2 \\
\hline M11 & M04 & 1.1E-08 & 1.6E-04 & 180 & 104 & 2.24 & 135 & 8 & - & 59 & 3 \\
\hline M11 & M06 & 9.4E-09 & 1.3E-04 & 149 & 64 & 2.20 & 199 & 9 & 182 & 347 & 4 \\
\hline M11 & M07 & 1.3E-07 & 2.7E-04 & 126 & 169 & 2.42 & 218 & 20 & 187 & - & 6 \\
\hline M13 & M15 & 2.3E-09 & 3.7E-04 & 15 & 95 & 2.18 & 285 & 15 & - & 78 & 7 \\
\hline M13 & M20 & 9.5E-10 & 3.7E-04 & 15 & 85 & 2.26 & 420 & 5 & - & 65 & 9 \\
\hline M13 & M21 & 2.0E-08 & 4.2E-04 & 99 & 11 & 2.28 & 50 & 23 & 54 & 150 & 10 \\
\hline M13 & M22 & 9.1E-10 & 6.2E-04 & 78 & 20 & 2.17 & 365 & 40 & 75 & - & 8 \\
\hline M15 & M01 & 1.8E-07 & 2.4E-04 & 409 & 55 & 2.59 & 63 & 20 & 21 & 42 & 19 \\
\hline M15 & M13 & 7.9E-08 & 3.4E-04 & 17 & 95 & 2.13 & 120 & 14 & 120 & 65 & 2 \\
\hline M15 & M17 & 3.6E-07 & 1.4E-04 & 50 & 50 & 2.45 & 54 & 21 & - & - & 15 \\
\hline M15 & M20 & 7.5E-08 & 1.9E-04 & 120 & 35 & 2.50 & 116 & 19 & 53 & 95 & 12 \\
\hline M16 & M05 & 1.1E-10 & 8.7E-04 & 132 & 41 & 2.02 & 989 & 49 & 10 & 60 & 11 \\
\hline M16 & M12 & 5.1E-11 & 7.8E-04 & 89 & 75 & 2.23 & 18 & 9 & 22 & 21 & 1 \\
\hline M16 & M19 & 6.8E-08 & 8.9E-04 & 20 & 175 & 1.97 & 116 & 25 & 89 & 5 & 7 \\
\hline M16 & MP5 & 6.7E-08 & 3.2E-04 & 174 & 85 & 2.27 & 108 & 17 & 36 & 25 & 4 \\
\hline M16 & MP6 & 1.5E-10 & 4.4E- 04 & 140 & 320 & 2.35 & 978 & 19 & 61 & 13 & 4 \\
\hline M19 & $\mathrm{MO2}$ & 1.2E-09 & 5.9E-04 & 53 & 137 & 2.13 & 219 & 11 & 15 & 2 & 2 \\
\hline M19 & M16 & 4.8E-07 & 4.5E-04 & 15 & 169 & 2.12 & 66 & 24 & - & 12 & 6 \\
\hline M19 & M21 & 3.0E-10 & 6.0E-04 & 41 & 128 & 2.06 & 210 & 12 & 31 & 3 & 2 \\
\hline M19 & M22 & 1.1E-07 & 4.0E-04 & 145 & 124 & 2.06 & 48 & 15 & 21 & 16 & 2 \\
\hline M19 & MP6 & 1.2E-07 & $3.5 \mathrm{E}-04$ & 172 & 353 & 2.14 & 97 & 21 & 28 & 12 & 6 \\
\hline M20 & M07 & 4.6E-11 & 2.4E-04 & 70 & 10 & 2.27 & 1194 & 27 & 29 & - & 6 \\
\hline M20 & & 4.6E-07 & 1.3E-04 & 100 & 100 & 2.38 & 176 & 31 & - & - & 14 \\
\hline M2O & & $E-10$ & $2.0 \mathrm{E}$ & 108 & 58 & 2.20 & 40 & 24 & 31 & 122 & 6 \\
\hline M2O & & E-10 & $2.0 \mathrm{E}$ & 201 & 2 & 2.31 & 420 & 17 & 18 & - & 1 \\
\hline M2O & & & & 232 & 6 & 2.47 & 1572 & 38 & 209 & - & 11 \\
\hline M21 & & $=-08$ & $4.0 \mathrm{E}$ & 17 & 166 & 1.87 & 102 & 35 & 303 & 7 & 9 \\
\hline M21 & & E-08 & 5.2E-04 & 12 & 450 & 2.42 & 273 & 26 & - & 15 & 4 \\
\hline MP5 & M04 & 6.9E-08 & 5.3E-04 & 43 & 189 & 2.19 & 160 & 33 & 29 & 10 & 6 \\
\hline MP5 & 106 & 3.7E-07 & 3.0E-04 & 17 & 244 & 2.17 & 83 & 34 & - & 24 & 9 \\
\hline MP5 & 107 & 1.2E-12 & 4.3E-04 & 106 & 81 & 2.22 & - & 15 & 14 & 32 & 1 \\
\hline MP5 & IP4 & 3.6E-07 & 2.1E-04 & 317 & 4 & 2.29 & 94 & 27 & 17 & 322 & 7 \\
\hline MP5 & PF6 & 1.7E-07 & 2.0E-04 & 34 & 250 & 2.21 & 128 & 33 & - & 17 & 8 \\
\hline MP6 & M07 & 9.9E-09 & 8.9E-05 & 397 & 10 & 2.20 & 322 & 30 & 33 & - & 8 \\
\hline MP6 & M21 & 2.5E-09 & 1.9E-04 & 332 & 25 & 2.24 & 253 & 26 & 25 & 120 & 11 \\
\hline MP6 & MP4 & 2.7E-08 & 1.6E-04 & 380 & 16 & 1.95 & 194 & 15 & 12 & 108 & 8 \\
\hline
\end{tabular}


Table 1: Parameter estimates and relative errors on parameters for the best fit between HES field data and model. The symbol "-" for relative error corresponds to parameters fixed by user in mathematical optimization procedure. 